\title{
NBSIR 76-1095
}

\section{Properties and Interactions of Oral Structures and Restorative Materials}

James M. Cassel

Dental and Medical Materials Section

Polymers Division

Institute for Materials Research

National Bureau of Standards

Washington, D. C. 20234

Annual Report for Period:

July 1,1975 - June 30, 1976

July 1976

Issued August 1976

Prepared for

National Institute of Dental Research

Bethesda, Maryland 20014 


\section{PROPERTIES AND INTERACTIONS OF ORAL STRUCTURES AND RESTORATIVE MATERIALS}

James M. Cassel

Dental and Medical Materials Section

Polymers Division

Institute for Materials Research

National Bureau of Standards

Washington, D. C. 20234

Annual Report for Period:

July 1, 1975 - June 30, 1976

July 1976

Issued August 1976

Identification of commercial materials or equipment in this report does not imply recommendation or endorsement by the National Bureau of Standards

Prepared for

National Institute of Dental Research

Bethesda, Maryland 20014

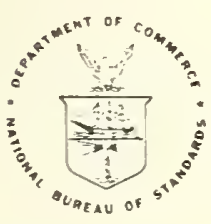

U.S. DEPARTMENT OF COMMERCE, Elliot L. Richardson, Secretary Edward O. Vetter, Under Secretary

Dr. Betsy Ancker-Johnson, Assistant Secretary for Science and Technology

NATIONAL BUREAU OF STANDARDS, Ernest Ambler, Acting Director 

ABSTRACT i

SUMMARY ii

INTRODUCTION

TECHNICAL REPORT 2

I. Adhesion of Restorative and Caries-Preventive

Materials to Tooth Surfaces 2
A. Surface Characterization of Dental Materials by Water Adsorption
B. Novel Approach to Development and Assessment of Adhesion in Dental Materials
C. Synthesis for Improved Adhesion and Stability of Composite Restorative and Sealant Materials
D. Techniques for Bonding to Mineralized Collagen Surfaces

II. Physical Properties of Hard Tissue and Dental Materials 50

A. Dimensional Change Measurements 50

B. Wear Resistance of Restorative Materials 54

C. Base Metal Alloy Research 58

REFERENCES 

Figure 1: Tensile strength comparison for coating agents consisting of NPG-GMA $\left(^{*}\right)$ and TI-2A ( + ) as a function of surface concentration of particulate using composites whose polymerization had been light-initiated.... 15

Figure 2: Tensile strength as a function of $f^{2 / 3}$ for averages of replicate specimens of NPG-GMA coated HA in Bis-

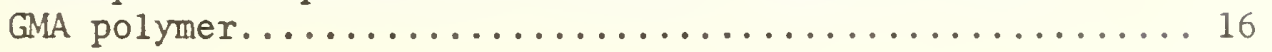

Figure 3: Tensile strength as a function of $f^{2 / 3}$ for averages of replicate specimens of uncoated $\mathrm{HA}$ in Bis-GMA

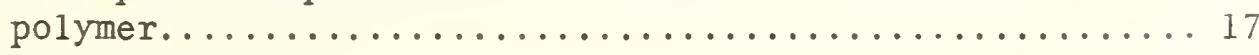

Figure 4: Tensile strength as a function of fraction ( $f$ ) of particulate plotted for individual points. Specimens consisted of trimethacryl titanate coated HA in Bis-

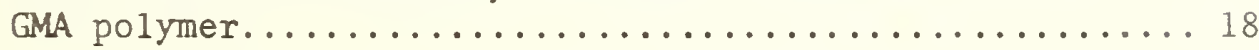

Figure 5: Tensile strength as a function of $\mathrm{f}^{2 / 3}$ for averages of replicate specimens of trimethacryl titanate coated HA

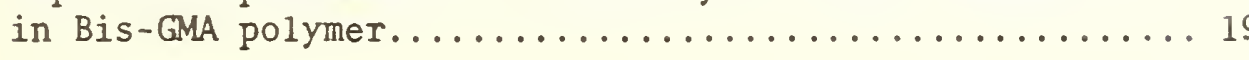

Figure 6: Tensile strength as a function of fraction (f) of particulate plotted for individual points. Specimens consisted of silane coupling agent (A-175) coated HA

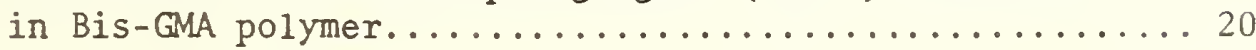

Figure 7: Tensile strength as a function of $\mathrm{f}^{2 / 3}$ for averages of replicate specimens of silane coupling agent (A-175)

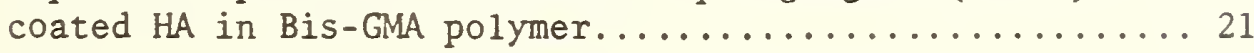

Figure 8: Tensile strength as a function of fraction (f) of particulate plotted for individual points. Specimens consisted of HA precoated with four times the customary molar concentration of silane coupling agent (A-175)

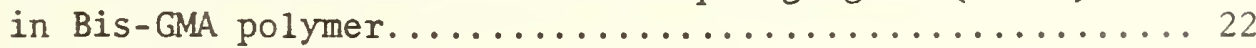

Figure 9: Tensile strength as a function of $f^{2 / 3}$ for averages of replicate specimens of silane coupling agent (A-175) at four times the customary concentration coated on $\mathrm{HA}$

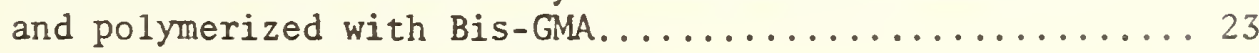

Figure 10: "Thermal expansion" of three dental amalgams.........53 

ABSTRACT

A diversity of techniques is being directed toward development of new and improved dental restorative and caries-preventive materials. These have included: surface characterization of dental materials and coupling agent-coated hydroxyapatite by water adsorption; further evaluation of a novel testing approach for investigating the adhesive capability of coupling agents; synthesis of selected monomers for potential application as components of a dental composite restorative system or a pit and fissure sealant application; and investigation of techniques such as grafting with 2 -cyanoacrylates and urethanes containing free isocyanate groups for modifying natural tooth and bone surfaces so as to achieve a more compatible surface for adhesion. Failure of the data acquisition and control system of a prototype pin on disc in vitro wear test procedure for dental restorative materials to record data consistently and to maintain proper measurement point trigger position have dictated construction of a new wear test unit that incorporates the successful design of the prototype unit, but that will allow for testing of multiple specimens and should permit data to be accumulated with a confidence level of $95 \%$, as compared to the $90 \%$ level previously attained. Procedures have been developed for the investigation of non-precious alloys used in crown and bridge application. 
SUMMARY

The research on dental materials that is described in this report is a part of a larger total effort that is carried out in collaboration with the American Dental Association Health Foundation. Also part of this collaborative effort through support funding and/or assignment of research personnel are the Armed Services Dental Corps. In addition, the National Association of Dental Laboratories, representing some 3,000 prosthetic laboratories, is a participant via the research associate program of the National Bureau of Standards.

While the bulk of the research progress in this report represents the efforts of persons supported under the Interagency Agreement with NIDR, there will of necessity be a degree of contribution that originates through the intentionally strong interaction among all persons participating in this collaborative dental program.

The objective is to effect improved dental health through development of new knowledge and better understanding of mechanical, chemical, and physical properties of restorative and caries-preventive materials and their interaction or relationship with the natural components of the oral structure.

A wide variety of techniques has been brought to bear to develop new approaches by which adhesive restorative dental materials might be developed. These have included surface characterization, development of a new approach to evaluation of the adhesive capability of coupling agents, synthesis of selected monomers for potential application as components of a dental composite restorative system or a pit and fissure 
sealant application and investigation of techniques such as grafting for modifying natural tooth and bone surfaces so as to achieve a more compatible surface for adhesion. A wear-generating and recording system has been redesigned to permit collection of larger amounts of data bearing on the wear resistance of dental materials. Procedures have been developed for the investigation of non-precious alloys used in crown and bridge application.

Water adsorption isotherms have been determined on most of the coated hydroxyapatite (HA) filler materials used in the investigation of an indirect method designed to assess the potential for adhesion to tooth surface of selected "coupling" agents. Addition of "coupling" agents, whether they be good or poor adhesives for $\mathrm{HA}$, has been found to reduce the adsorption capacity of the HA and of experimental composites formulated with the resin Bis-GMA.

A technique has been developed that has improved the precision in a novel adhesion testing procedure for examination of coupling agents that can bond a resin composite system to tooth enamel. Test specimens consisting of a resin matrix in which are dispersed varying amounts of hydroxyapatite powder that has been coated with a coupling agent of interest have been shown to give much less variable tensile strength results if the resin matrix has been polymerized via a UV initiator rather than by a chemical free radical-producing reaction. With the modified technique, isopropyltrimethacryl titanate and 3-methacryloxypropyltrimethoxy silane have been demonstrated to have potential for coupling Bis-GMA composites to tooth enamel.

Investigation of an ether-ester linked, highly purified dimethacrylate 
monomer system as a potential dental composite restorative resin has continued. Of the three isomeric 2-methacryloxyethyl(2-methacryloxyethoxybenzoates) that comprise the eutectic mixture, the synthesis and purification of reasonable quantities of the ortho isomer has proven most troublesome and alternate synthesis paths are being examined.

A number of functional monomers (monomers with pendant groups capable of reaction with mineralized tissue) have been synthesized. The initial synthesis of ortho (2-methacryloxyethoxy) benzoic acid produced a mixture of products too difficult to separate and a modification of that synthesis procedure is being explored. The ortho (2-methacryloxyethoxy) benzaldehyde has been synthesized and purified satisfactorily to give us the ortho and para derivatives of this series. The meta isomer, with a melting point near room temperature, has not yet been satisfactorily purified. The intent is to investigate a proper admixture of these isomeric, aldehyde-containing monomers for ability to bond to tooth structure and for application as dental composite and sealant systems. A high purity (crystalline solid) 4-(methacryloxyethyl)-2-isocyanotoluene urethane, as well as one with an analogous aliphatic cyclic structure, have been prepared. We have copolymerized these urethane-methacrylateisocyanate containing systems with Bis-GMA and will explore the capability for bonding to dental or bone surfaces.

Further work on functional monomers with potential as cariostatic agents has included investigation of two types of fluorine-containing monomers. The $\mathrm{F}^{-}$release ratio in water is being determined for homopolymers and copolymers of 2-methacryloxypentafluorobenzene and similar monomers. These polymers contain potential phenolic hydroxyls (through loss of fluorine) which may assist in achieving adhesion to the tooth 
surface. Pentadecafluorooctyl methacrylate, which has been shown to copolymerize with the Bis-GMA monomer system, may have potential as a linear resin since it confers hydrophobic character to hard tissue surfaces.

A polyfunctional surface-active agent with capability for a chelation type interaction with tooth surface and which is also an amine accelerator for Bis-GMA, as well as an initiator for cyanoacrylate monomer polymerization, has been prepared.

To reduce the polymerization shrinkage that occurs as a result of having to thin a commercial Bis-GMA with a less viscous comonomer, we have synthesized large molecular weight (e.g. 1000 and 2000) dimethacrylates. However, the system's viscosity has not yet been reduced to a workable level by this approach.

Grafting to the collagenous component of hard tissue continues to offer a potentially useful route to adhesion. Ultraviolet initiated polymerizations are particularly of interest as a means of attaining reaction on the time scale required for dental application. We have examined the curing characteristics of various formulations containing Bis-GMA, different monomer diluents and varied concentrations of UV initiator. A photocrosslinking monomer has shown promise as a means of reducing the strain-inducing extraction that occurs on storage in water of the cured formulations.

In the investigation of grafting of 2-cyanoacrylates and urethanes containing free isocyanate groups sufficiently rapid curing techniques have been developed for dental application, but the bond strengths developed between bovine dentin and restorative filling material using pure monomer systems have been low--a result attributed to the inability of these particular formulations to serve as gap fillers in an application, 
e.g. as dental cements, where perfect matching or fit of opposing surfaces is difficult to achieve. To provide a more rapid screening test for this effort, a test procedure has been developed that employs carefully-machined, flat-surfaced bone cylinders which can be gripped in the tensile strength device without having to imbed the specimen in a resin holder. With the rapid screening test, a number of commercial as well as experimental cyanoacrylates and other adhesion-promoting agents have been examined. One promising viscous formulation of isoamylcyanoacrylate gives a bond strength to bone after one day in water of about two-thirds the strength that can be achieved by applying a composite resin to an etched enamel surface.

Attenuated total reflectance I. R. measurements indicate that attachment of the 2-cyanoacrylates to bone surfaces is principally by physical rather than chemical, e.g. covalently bonded, process. On the other hand, a synthesized isocyanate containing a methacrylate moiety, when cured on a bone surface, has remained detectable on that surface by I. R. after extended extractions by various organic solvents. Since this cured system in the absence of bone is not soluble in solvents that have been studied, the proof for true grafting to the substrate will be difficult to ascertain.

Information related to reactions in dental amalgams has been obtained from measurements of their thermal expansion. Non-equilibrium thermal expansion curves have been determined for amalgams obtained from a lathe cut alloy, a copper dispersion alloy, and a spherical alloy. The results support the hypothesis that phase changes are producing dimensional changes and either the phases, the relative amounts of the different phases, or the rates of change are different in the different amalgams. 
A prototype in vitro wear test previously reported on has given promise for investigation and evaluation of the "wear" potential of dental restorative materials. However, failure of the data acquisition and control system to record data consistently and to maintain proper measurement point trigger position have dictated construction of a new wear test unit that incorporates the successful design of the prototype unit, but that will allow for testing of three specimens rather than one and should permit data to be accumulated that will be reliable at a $95 \%$ or greater confidence level as compared to the $90 \%$ level that was reached with the prototype. Construction of the new instrument is virtually complete.

A study has been initiated with the objectives of determining the characteristics of base metal casting alloys and accessory materials related to the serviceability of these alloys for use in cast crowns and bridges, of determining the effects of fabrication techniques on the properties of the castings, and of utilizing this information for the development of improved techniques and for guidance for development of improved alloys. Laboratories have been fitted for addressing the problems involved in achieving precision castings and in the bonding of porcelain to metal. A prototype die design and a pattern production technique essential to the definition of casting accuracy have been tested and appear highly suitable. Five hardened stainless steel copies of the prototype are now in use. In order to assure that the techniques used represent the best of the state of the art in pattern production, investing and casting procedures, visits are being made to a number of manufacturers' research laboratories and prosthetic dental laboratories. While castings in our own laboratories have tended to err in the undersize 
direction, insofar as accuracy and reproducibility are concerned, techniques being used are equal or superior to those used elsewhere.

We have observed that phosphate bonded investments are associated with metal casting surfaces that are systematically rougher than the surface of metals cast into gypsum bonded investments. Steps are being taken to quantify surface roughness by profilometer, optical, and scanning electron microscopy.

We have measured the dimensional change on setting of eight investments so that relationships between this characteristic and the accuracy of castings can be determined. To supplement this data, apparatus has been ordered for measurement of the thermal expansion of investments, alloys, and porcelain. 
The National Bureau of Standards is primarily a measurement organization. Paths from measurement to improved dental service lead from measurement and characterization to development of new techniques for using materials, to laboratory prototypes of improved materials and devices, to clinical evaluation and, finally, commercial production by industry:

The dental research program at NBS is a cooperative effort both in personnel and funding, involving several agencies of government and the American Dental Association. The bulk of other agency support for the total program derives from the National Institute of Dental Research.

The research reported in the following pages is only that portion of the NBS dental program which is supported by interagency agreement.

The objective of the research effort discussed briefly in the following pages is to effect improved dental health through development of new knowledge and better understanding of the mechanical, chemical and physical properties of the components of teeth and bone, as well as materials used or potentially of use in restorative and preventive dental practices.

An outline of the research as approved in the interagency agreement is given below, along with participating personnel.

I. Adhesion of Restorative and Caries-Preventive Materials to Tooth Surfaces

A. Surface Characterization of Dental Materials by Water Adsorption -- Dr. W. V. Loebenstein

B. Novel Approach to Development and Assessment of Adhesion in Dental Materials -- Dr. W. V. Loebenstein and Mr. J. W. Kumpula

C. Synthesis for Improved Adhesion and Stability of Composite Restorative and Sealant Materials -- Dr. J. M. Antonucci

D. Techniques for Bonding to Mineralized Collagen Surfaces -Dr. G. M. Brauer and Mr. D. J. Termini

II. Physical Properties of Hard Tissue and Dental Materials

A. Dimensional Change Measurements -- Mr. G. Dickson

B. Wear Resistance of Restorative Materials -- Mr. G. Dickson and Dr. J. M. Powell (USAF)

C. Base Metal Alloy Research -- Mr. G. Dickson, Dr. G. T. Eden (USN), Mr. 0. M. Franklin (USN), Dr. J. M. Powell (USAF), Dr. Y. Ohta (Guest Worker, Japan), Dr. R. W. Bauer (National Association of Dental Laboratories), Mr. C. P. Mabie (American Dental Association Health Foundation Unit) 
I. Adhesion of Restorative and Caries-Preventive Materials to Tooth Surfaces

\section{A. Surface Characterization of Dental Materials by} Water Adsorption

One of the more important objectives of the water vapor adsorption investigation insofar as dental and medical materials are concerned is to characterize the role of the coupling agent which exists at the interface between a solid (inorganic) phase and the polymer matrix to which it is attached. The solid phase can be either the filler material in a dental composite or the dental hard tissue, itself, to which the resin (or composite) may have been polymerized. Reference is made to a recent publication originating in this laboratory in which the theory was developed for explaining the complicated behavior of mixed adsorbents such as these in terms of the adsorption of the individual components of which they are comprised.

Water vapor was selected as the adsorbate because: (a) dental and medical materials are continuously bathed in an aqueous environment; (b) prolonged exposure to water is known to weaken adhesive materials used in dentistry; and (c) the fact that dental polymers are completely (1) permeable to water vapor (which may not be equally true for other commonly used adsorbates).

The mixed adsorbent that has been studied extensively here is a composite consisting of NPG-GMA ${ }^{*}$ coated hydroxyapatite (HA) dispersed in

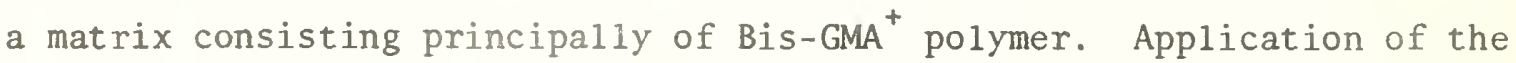

* $\mathrm{N}$-(2-hydroxy-3-methacryloxypropy 1$)$-N-phenylglycine

+ Described by R. L. Bowen as the addition product of bisphenol $A$ and glycidyl methacrylate 
Brunauer, Emmett, and Teller (BET) adsorption equation (Eys. 6-9 of Ref. 1) to the data for NPG-GMA COATED HA' gave rise to a surface area of 12.4 $\mathrm{m}^{2} / \mathrm{g}$. It is significant that this is barely $1 / 3$ of the area of the uncoated HA. A composite consisting of six percent of this coated HA (as component 2) with Bis-GMA polymer (as component 1) accounted for a BET area (available to water vapor) of $35.3 \mathrm{~m}^{2} / \mathrm{g}$. Application of Eq. 13 of reference 1 showed this to be consistent with an area of $36.8 \mathrm{~m}^{2} / \mathrm{g}$ for component 1. It also agreed with the value obtained by a weighted average, indicating the validity of additivity in this system. That surface area agreed to within $61 / 2$ percent of the value obtained experimentally for another sample of Bis-GMA reported in the same reference. (The c-value, related to the heat of adsorption, was 3.5 in this work, however, as compared with 0.85 reported earlier.)

A second composite consisting of the same two components, but with 36 percent of component 2, was simultaneously studied by water vapor adsorption. Based on the considerations above, namely, the adsorptive characteristics of the individual components, it was possible to predict that the surface area available to water for this composite should be $28 \mathrm{~m}^{2} / \mathrm{g}$. While the BET values were unattainable because of curvature of the plot, points higher on the isotherm and, hence, applicable to the Harkins and Jura (H-J) adsorption equation (discussed on p. 46 of ref. 1) confirmed a surface area of $26.4 \mathrm{~m}^{2} / \mathrm{g}$ in reasonably good agreement with the predicted value.

Adsorption isotherms have been obtained for most of the coated HA filler materials used in formulating experimental composites in connection with the indirect method for evaluating and comparing coupling agents (Part B of this section). This practice is being continued as the work 
progresses and new coupling agents enter the picture. What can be said so far regarding their adsorptive characteristics is that both coupling agents and release agents, when applied to adsorbent surfaces, reduce the effective surface area by interaction (interference with access of the adsorbate molecule - also discussed throughout reference 1). Furthermore, the filler component, so modified, appears to retain its newly acquired adsorptive characterizing parameters (most important of which is surface area) regardless of what proportions may be used in making up the composite.

A polymerized test specimen consists of three components: HA, coupling agent, and Bis-GMA. In applying the rule for combining the surface properties of components pair-wise (Eqs. 11 and 12 of ref. 1) to obtain the results observed for the combined aggregate, it should make no difference in the final outcome whether the coupling agent is considered to be combined first with the monomer or with the HA. There is interaction between the coupling agent and the HA resulting in a significant reduction of the surface area of the coated HA regardless of whether the coupling agent is a good or poor adhesive. It is not anticipated that a mixture of coupling agent with monomer alone (without $\mathrm{HA}$ ) would result in a polymer whose water adsorptive properties would be much different from that of the polymer alone - although this experiment should be performed and is planned for the near future. An aggregate formed between HA and polymer alone (i.e. without coupling agent) consistently gives a larger surface area available to the water molecule than when the HA had been precoated with coupling agent. It is possible that the solution of coupling agent in solvent such as acetone, hexane, or ethyl acetate can penetrate into interstices, pores, etc. before evaporation of the solvent, leaving the 
coupling agent deposited upon many water-adsorbing sites of the HA which are inaccessible to the viscous monomer. This may be what the adsorption measurements are telling us. Another possibility is that the coating agent, itself, through some mechanism not yet understood, if dissolved in the Bis-GMA monomer prior to polymerization would be capable of lowering the surface area of the polymerized product appreciably from that of BisGMA alone. 
B. Novel Approach to Development and Assessment of Adhesion in Dental Materials

The initial phase of the novel method for comparing tensile strengths of coupling agents between dental hard tissue and polymerized acrylic resin has been described in the Annual Report for FY 1975

That information was prepared for submission as an IADR presentation and for publication. While the results of that initial phase have established that the concept is both feasible and sound, improvement is definitely indicated in decreasing the magnitude of the experimental error. This is recognized as the most important single factor to be resolved before a general acceptance of the procedure can be expected. It has been stated previously that the method of polymerization which consisted of mixing equal weights of the aromatic amine containing monomer preparation with the benzoyl peroxide containing monomer preparation contributed in several ways to the ultimate variability in tensile strength of the polymerized specimen. This variability within replicate specimens' strengths was just as great whether the final product was a composite or whether it was clear resin, alone. When it was a composite, the variability within replicates was independent of the concentration of particulate. This eliminated one possible source of error, namely, the step in which the particulate is mixed into each monomer separately. As much time as is necessary to obtain a thorough and uniform dispersion can be taken during this operation. In contrast to it is the following step in which the two monomer preparations are mixed, thus initiating the polymerization process. This latter mixing must be done quickly before the thickening begins. If insufficient mixing occurs, uniform distribution of the amine and the peroxide will not occur, leading to incomplete polymerization. If the mixing is more than sufficient, and the pouring of the specimen molds is 
accomplished with a partially polymerized mixture, the rupture of polymer bonds may occur, resulting in weakening of the specimen. Finally, the need for speed almost invariably results in the introduction of bubbles which have insufficient time to rise to the surface and break before they are entrapped in the polymerized specimen. Of course, visual inspection of the specimens enables some of these imperfect ones to be detected and discarded, although some undoubtedly must escape detection.

For an entirely different reason than those already discussed, an alternative to the amine-peroxide system seemed worthy of investigating. This had to do with the fact that the monomer preparations underwent some change during long periods of storage such that the tensile strength of a polymerized specimen was not constant. It was a reasonable speculation that this change was brought about by the deterioration of the benzoyl peroxide.

The present direction of this study is along the lines of an alternate polymerization-initiating mechanism. Light activation of benzoin methyl ether as a means of initiating the polymerization of Bis-GMA for sealant application was described by Buonocore. The first use in the present work was to polymerize into test specimens, independently, each of the two monomer preparations - that containing the aromatic amine and the other preparation containing the benzoyl peroxide. In all cases, a two percent benzoin methyl ether composition was used. Exposure to UV was accomplished in three steps in order that a depth no greater than one mm need be exposed at any one time.

The average tensile strengths were $17.27 \times 10^{6} \mathrm{~N} / \mathrm{m}^{2}\left(1.727 \times 10^{8}\right.$ dynes $/ \mathrm{cm}^{2}$ ) for the aromatic amine-containing polymerized monomer preparation, but only $3.50 \times 10^{6} \mathrm{~N} / \mathrm{m}^{2}$ for the benzoyl peroxide-containing 
polymerized monomer preparation, with a pooled standard deviation for error (within replicates) of $2.49 \times 10^{6} \mathrm{~N} / \mathrm{m}^{2}$.

It would appear that the deterioration in the tensile strength of the polymerized resin as a consequence of monomer aging was shared by both monomer mixes, but to a much greater extent by the benzoyl peroxidecontaining preparation. This is confirmed by the fact that specimens of clear resin polymerized during the early stages of this project (before the aging of the monomer preparations was evident) exhibited tensile strengths in the neighborhood of $30 \times 10^{6} \mathrm{~N} / \mathrm{m}^{2}$.

Two series of tensile strength (INSTRON) experiments were performed using in both series the aromatic amine-containing monomer which had been employed previously. Each series used light initiation for the polymerization. One series was performed with NPG-GMA as the precoat for the hydroxyapatite, while the other compared a new coating agent, namely, isopropyl dimethacrylic isostearic titanate, " designated here as (TI-2A). Fig. 1 compares the tensile strengths of both series as a function of surface concentration of particulate, $f^{2 / 3}$, for the averages of replicate values. The NPG-GMA (asterisks) shows a decidedly better performance than does the TI-2A (plus marks).

It may not be valid to compare the performance of NPG-GMA by the two methods of polymerization, especially at high particulate concentrations. It is possible that the particles of HA suspended in the monomer block off some of the light required to initiate the polymerization process. This may account for the peculiar way that the tensile strength curve falls off at higher values on the $\mathrm{f}^{2 / 3}$ scale after appearing almost horizontal. While this behavior, if real, is somewhat restrictive, it may only require a lower range of particulate concentrations.

* Kenrich Petrochemicals, Inc., Bayonne, N. J. 07002. 
A statistical test was made to determine whether the agreement between tensile strengths within replicates was more precise for specimens (of all particulate compositions) polymerized by the light-initiated method than by the amine-peroxide method employed in the earlier stages of this study. The latter work provided a mean-square deviation of $0.1218 \times 10^{14}$ $\left(\mathrm{N} / \mathrm{m}^{2}\right)^{2}$ with 218 degrees of freedom (df). For the two series of experiments using the light-initiated method, the mean-square deviation (within replicates) was on 1 y $0.0469 \times 10^{14}\left(\mathrm{~N} / \mathrm{m}^{2}\right)^{2}$ with $15 \mathrm{df}$. An F-ratio of 2.60 is significant at the five percent level, thus supporting the hypothesis that light-initiation leads to better precision.

Two specimens containing Bis-GMA, together with methyl methacrylate monomer as a thinner and no particulate material, were polymerized by lightinitiation in three layers, as described. Their tensile strengths were 25.2 and $25.6 \times 10^{6} \mathrm{~N} / \mathrm{m}^{2}$, respectively. This suggested that a monomer preparation of this type might better be used for the comparison studies that were planned.

All results subsequently referred to in this report were obtained by using Bis-GMA with a copolymerizable diluent to reduce the viscosity. In these experiments, the diluent consisted of ten percent methyl methacrylate (MMA) (triethylene glycol dimethacrylate would probably work just as well and have the additional advantages of low volatility and no odor). The photo-initiator consisted of benzoin methyl ether to the extent of two percent of the diluted Bis-GMA. It was the last component to be introduced before polymerization.

The particulate phase or filler consisted of hydroxyapatite, both uncoated and precoated with the particular agent under test. The weight fractions of filler were pre-determined to be more or less uniformly 
distributed between zero and five percent. This low range was a limitation of the method of polymerization in the expectation that the light would be able to penetrate the entire sample. After the filler was completely dispersed in the monomer, the mixture was allowed to stand overnight to permit bubbles to escape. The photo-initiator was then carefully mixed in and dumbbell-shaped split teflon molds were filled. Various methods of exposure to light were examined which included use of the NUVALight (L. D. Caulk Co.), and even direct sunlight. Most of these methods were abandoned because of the difficulty of reproducing the illumination conditions exactly. The method finally adopted for these tests and others that follow consisted of using a 275-watt 110-125 volt Westinghouse Sun Lamp (11GR401) shining vertically down upon the specimen at a height of $18 \mathrm{~cm}$ for a duration of 15 minutes. This was more than sufficient exposure to polymerize the entire specimen in one step even though the specimen was $21 / 2 \mathrm{~mm}$ in depth.

In contrast with the amine-peroxide polymerization procedure, the specimens were sufficiently free of defects that virtually none had to be rejected. This permitted better replication, and although scatter was not eliminated, it was appreciably reduced.

The results of the Instron tensile measurements are shown for the NPG-GMA coated and for the uncoated HA in Figs. 2 and 3 where linearity (when plotted as a function of $\mathrm{f}^{2 / 3}$ ) is brought out much more clearly than before. The points are averages of quadruplicates for the most part, with a few triplicates, for a total of 27 and 37 individual measurements, respectively. The coefficient of variation was below 30 percent.

It can be seen that a line fitted to the points of Fig. 2 would be approximately 50 percent less steep in slope than for Fig. 3, indicating 
that the coating agent NPG-GMA significantly reduced the drop-off in tensile strength. This order of placement for the two series agrees with the results of statistical curve fitting applied to the amine-peroxide system.

Application of the method was then made in testing coupling agents which showed promise of possibly exceeding NPG-GMA in adhesive strength. Two candidate coupling agents were investigated. The first of these, sopropyl tri methacryl titanate, has the structure shown:

$$
\left(\mathrm{CH}_{3}\right)_{2} \mathrm{CHOTi}\left(\mathrm{O}-\mathrm{C}-\mathrm{C}=\mathrm{CH}_{2}\right)_{3}
$$

and is manufactured by Kenrich Petrochemicals, Inc.

This material, identified by its manufacturer as "Ken React TTM$33 S^{\prime \prime}$ was coated on HA using ethyl acetate as a solvent and with the same molar concentration per $\mathrm{g}$ of $\mathrm{HA}$ as with all the other coating materials previously studied. Bis-GMA, with ten percent methyl methacrylate as the thinner, was the stock monomer as before. Weight fraction of filler was varied at $0.005(1 / 2$ percentile) increments up to $f=0.05$. Each batch of monomer plus filler, while only about $1 \mathrm{ml}$, was sufficient to form four or five polymerized tensile specimens. A plot of tensile strength against f for all 37 points is shown in Fig. 4. The graph shows tensile strength to be virtually independent of filler concentration. It should be emphasized throughout this investigation when comparing two series that the more negative (steeper) the slope, the poorer the coupling agent is. Therefore, the best that can be hoped for is zero slope. The apparent depression of the highest concentration point ( $5 \%$ value) may be real if the light from the sunlamp was incapable of completely penetrating the 
specimens due to insufficient backscattering by the filler particles. Fig. 5 is a plot of the replicate averages at each composition against $\mathrm{f}^{2 / 3}$ constructed to the same scale as used previously in order to compare with the corresponding plot for NPG-GMA (see Fig. 2).

The experimental error (i.e. within replicates) for all specimens of the titanate composites was $0.499 \times 10^{7} \mathrm{~N} / \mathrm{m}^{2}$ (or less than 5 megapascals). This corresponds to a coefficient of variation of $21 \%$, which is about a 50 percent improvement over the data obtained in earlier stages of this investigation using an amine-peroxide polymerization method.

A second coupling agent with promise to be examined and compared against NPG-GMA was a Silane coupling agent, 3-methacryloxypropyltrimethoxy silane, with the formula:

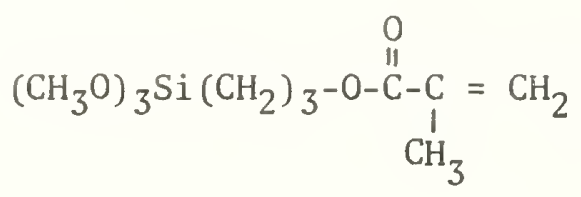

and which is designated A-175 by its manufacturer, Union Carbide Corp. It is recognized as a coupling agent used to coat glass beads in dental composites. Its selection was based on a similarity to the titanate in the assumed mechanism of attachment to both substrate and polymer. Two series of experiments were carried out with this coating agent. They differed only in the molar concentration of coupling agent applied to the HA. In the first instance, the same molar surface concentration was used as with previous agents - equivalent to the concentration of NPG-GMA just needed to cover the HA with a monolayer.

Tensile strengths for this series are shown in Figs. 6 and 7. Fig. 6 is a plot of all 43 points vs $f$ (similar to Fig. 4 for the titanate), while Fig. 7 illustrates the averages of replicates again plotted as a 
function of $\mathrm{f}^{2 / 3}$. Some unusually high tensile strength values for the clear resin (no filler present) mar an otherwise horizontal display, indicating again a virtual absence of dependence on composition. The coefficient of variation (for error) was $27 \%$ for this series.

The second series of experiments with this same silane coupling agent was performed using four times greater surface concentration than before. It was included to determine whether amounts greatly in excess of a monolayer might have a profound effect upon the resulting adhesion. These results are shown graphically in Figs. 8 and 9, which correspond in scale and abscissa to Fig. 4 and Fig. 5, and Figs. 6 and 7, respectively. This series corresponds to 45 different specimens, with a coefficient of variation (within replicates) of 23 percent. Again, no falling off of tensile strength with increasing filler concentration is evident. The average tensile strength for all specimens is $2.47 \times 10^{7} \mathrm{~N} / \mathrm{m}^{2}$, as compared with $2.84 \times 10^{7}$ for the normal dosage of Silane (see Fig. 6) and $2.39 \times 10^{7}$ for the titanate specimen (see Fig. 4). These mean values are not significantly different from one another, statistically.

It must be concluded, at least insofar as these dry specimens are concerned, that both the trimethacry titanate and the Silane appear to have the properties of superior adhesives in coupling HA to Bis-GMA.

The similarity in the behavior of the fourfold concentration of Silane coupling agent with that for the normal dosage has an additional significance - it verifies that this coupling agent could not have had any effect upon the degree of cross-linking of the Bis-GMA during polymerization. If cross-linking had been enhanced, it would have increased the tensile strength more with increased filler concentration. The argument might have been made that this increase exactly compensated a decrease 
that would otherwise have taken place in the absence of the cross-linking. If this had been so, however, the second series with increased silane concentration would have shown an up-trend in tensile strength with increasing $f$. 


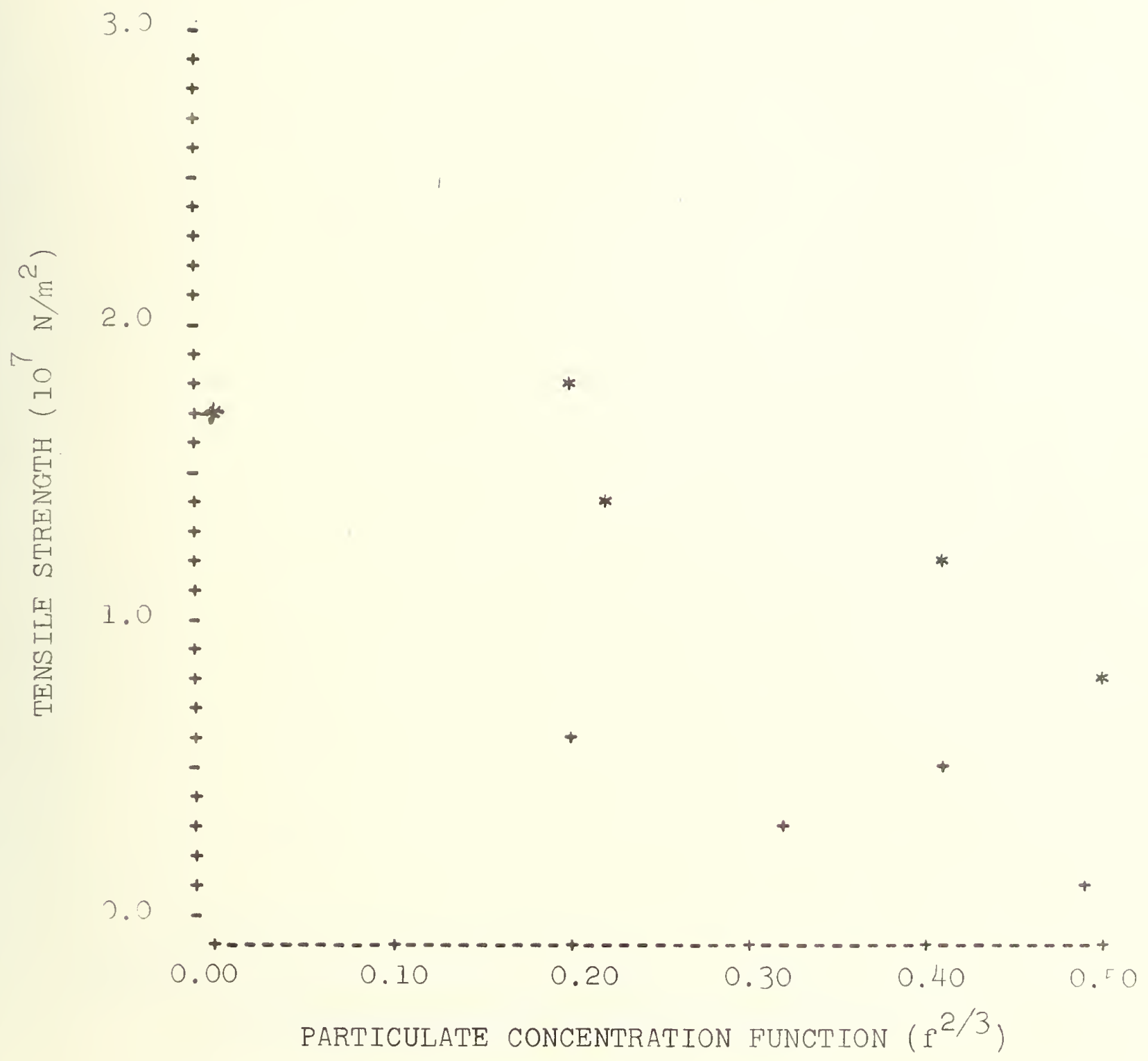

Fig. I : Tensile strength comparison for coating agents consisting of NPG-GMA (*) and TI-2A $(+)$ as a function of surface concentration of particulate using composites whose polymerization had been lightinitiated. (Most of tine points are averages of replicate determinations.) 


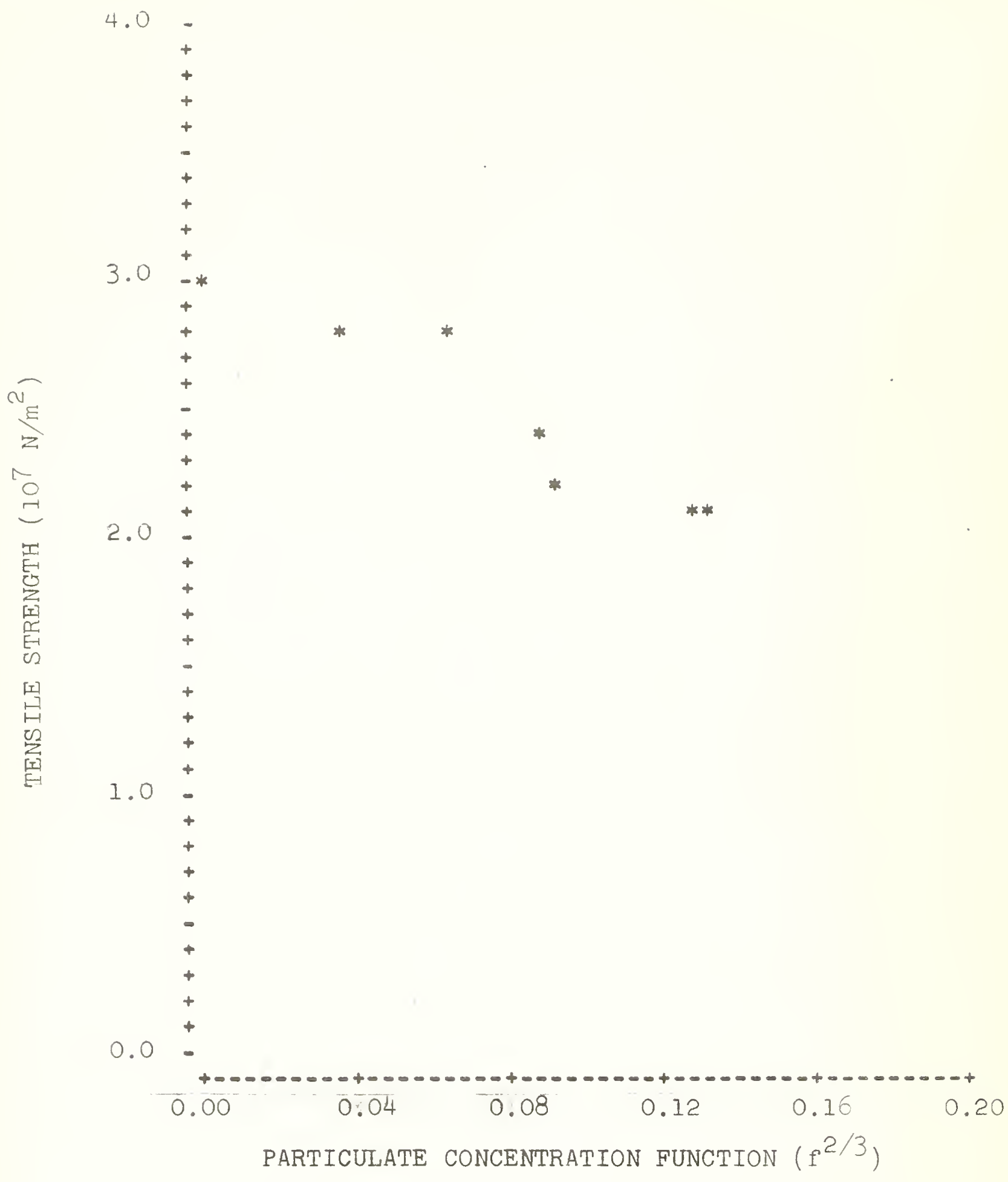

Fig. 2 : Tensile strength as a function of $\mathrm{f}^{2 / 3}$ for averages of

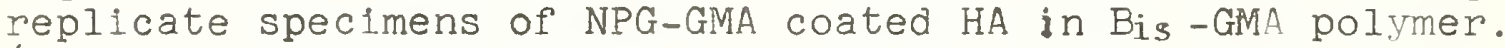

(Polymerization initiated by a single 15-minute exposure to sun lamp.) 


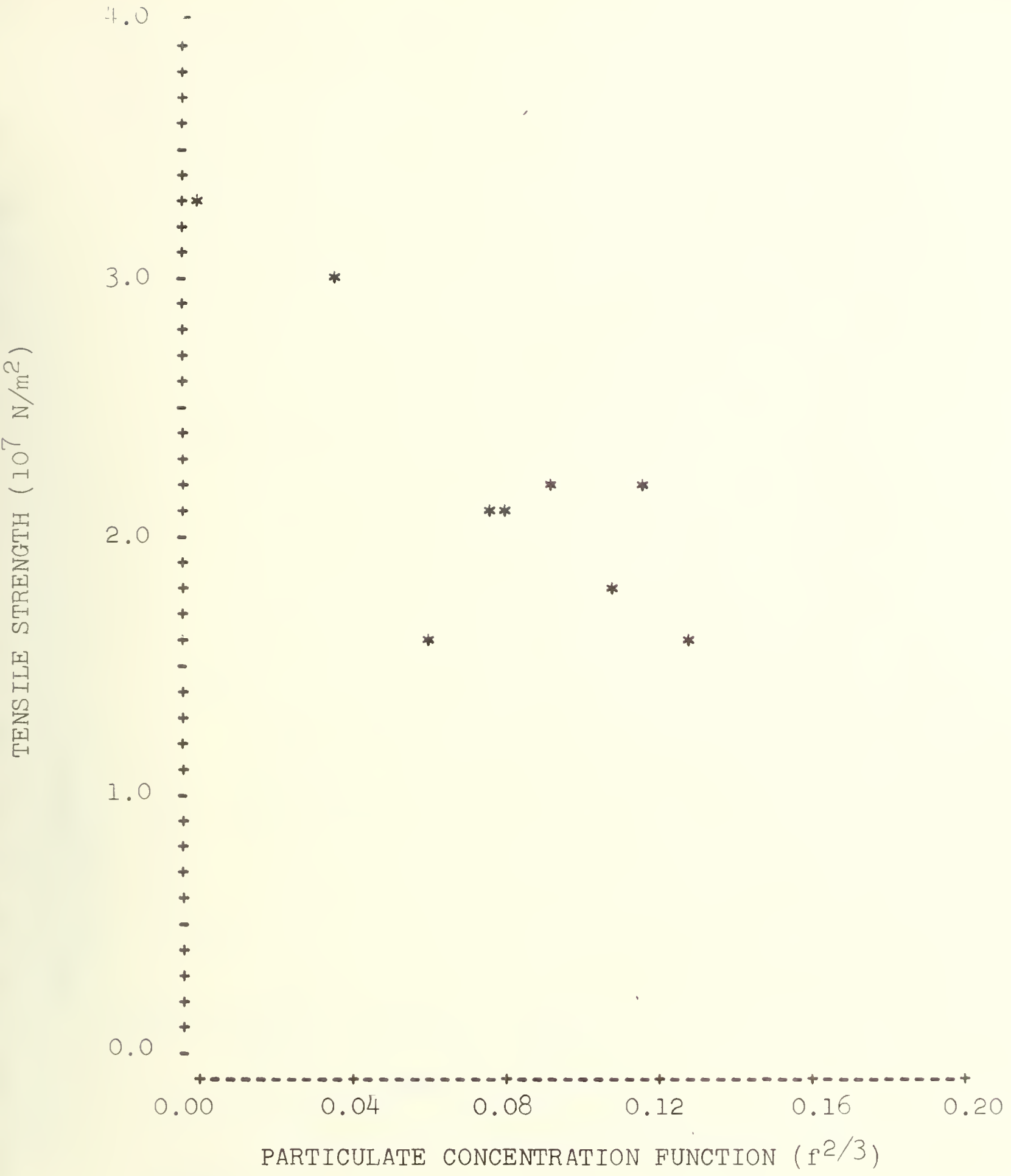

Fis. 3 : Tensile strength as a function of $\mathrm{f}^{2 / 3}$ for averages of replicate specimens of uncoated HA in Bis-GMA polymer.

(Polymerization initiated by a single IE-minute exposure to sun lamp.) 


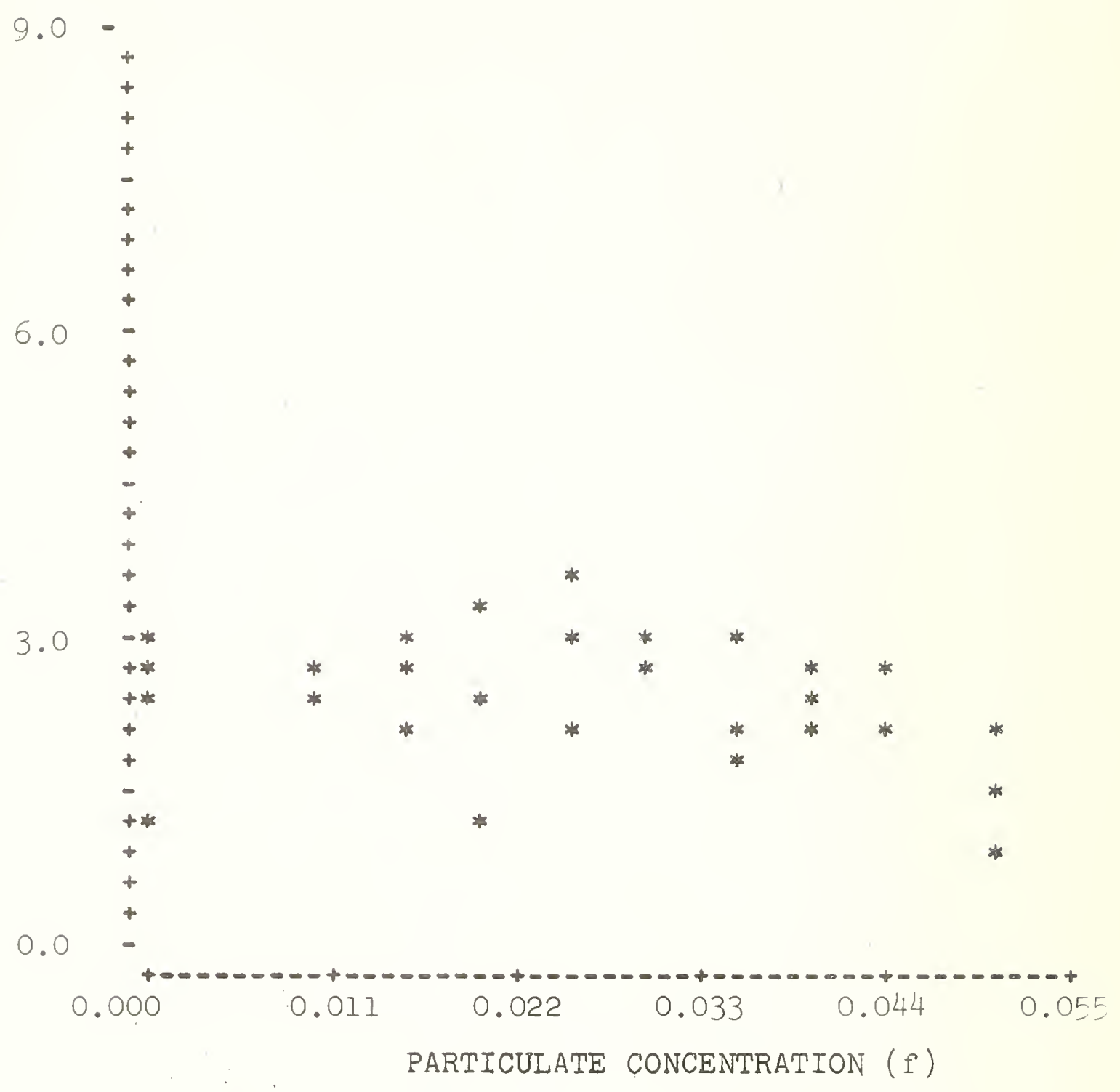

Fig. 4 : Tensile strength as a function of fraction ( $f$ ) of particulate plotted for individual points. Specimens consisted of trimethacryl titanate coated $\mathrm{HA}$ in $\mathrm{B}$ is-GMA polymer. (Polymerization initiated by a single 15 -minute exposure to sun lamp.) 


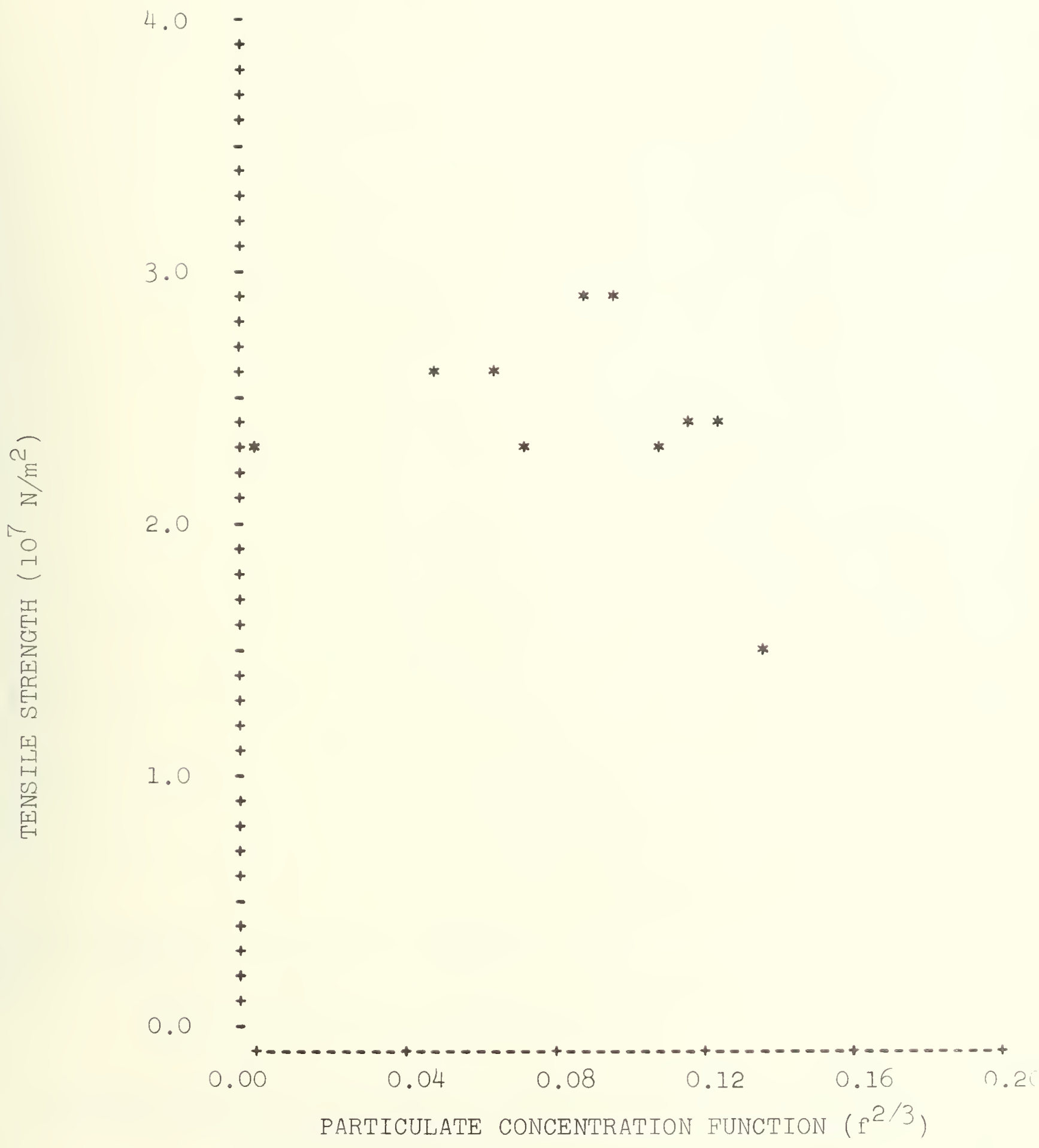

Fig. 5 : Tensile strength as a function of $f^{2 / 3}$ for averages of replicate specimens of trimethacryl titanate coated HA in Bis - GMA polymer.

(Polymerization initiated by a single 15-minute exposure to sun lamp. 


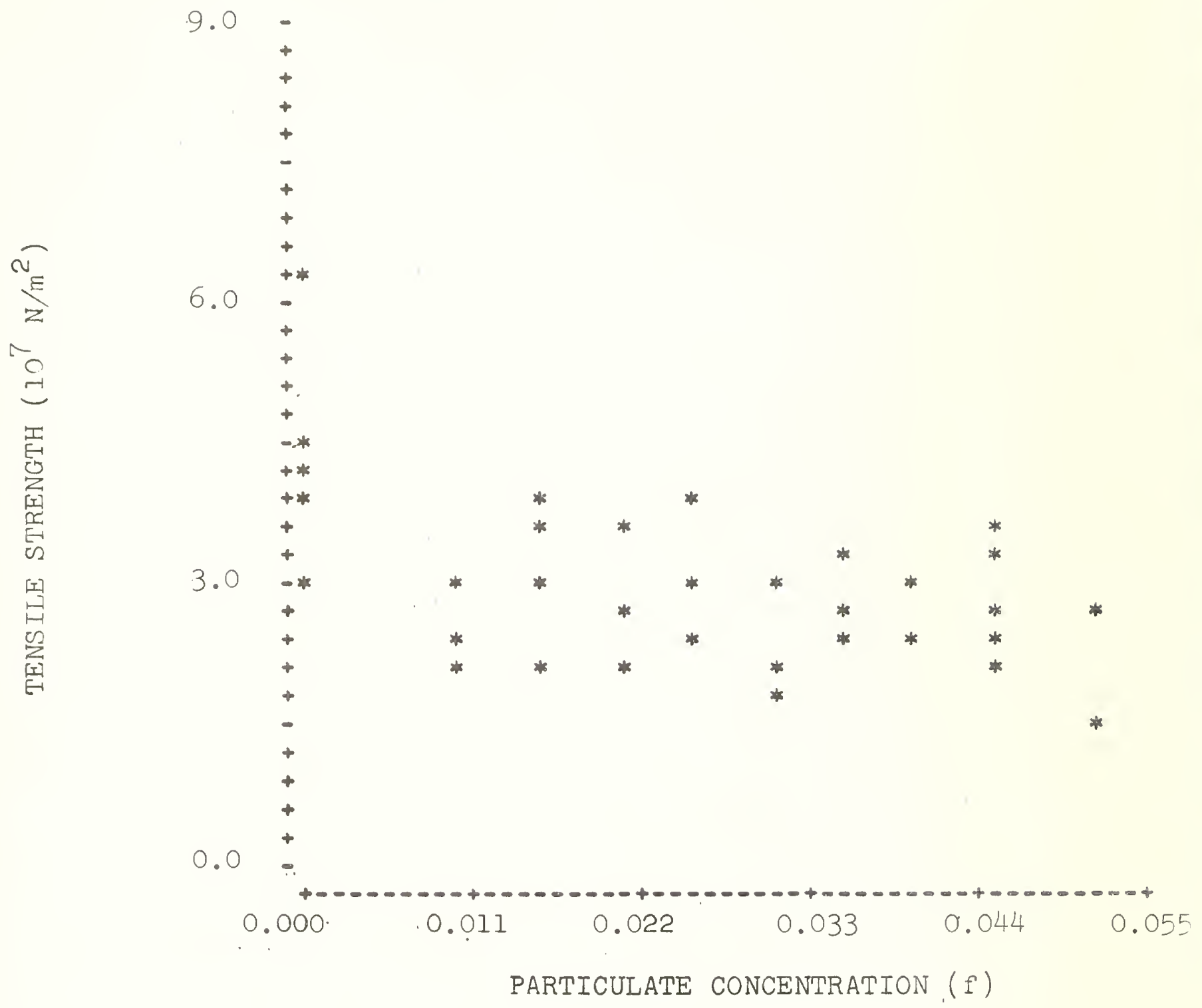

Pig. 6 : Tensile strength as a function of fraction ( $f$ ) of particulate plotted for individual points. Specimens consisted of silane coupling agent (A-175) coated HA in Bis-GMA polymer.

(Polymerization initiated by a single 15-minute exposure to sun lamp.) 


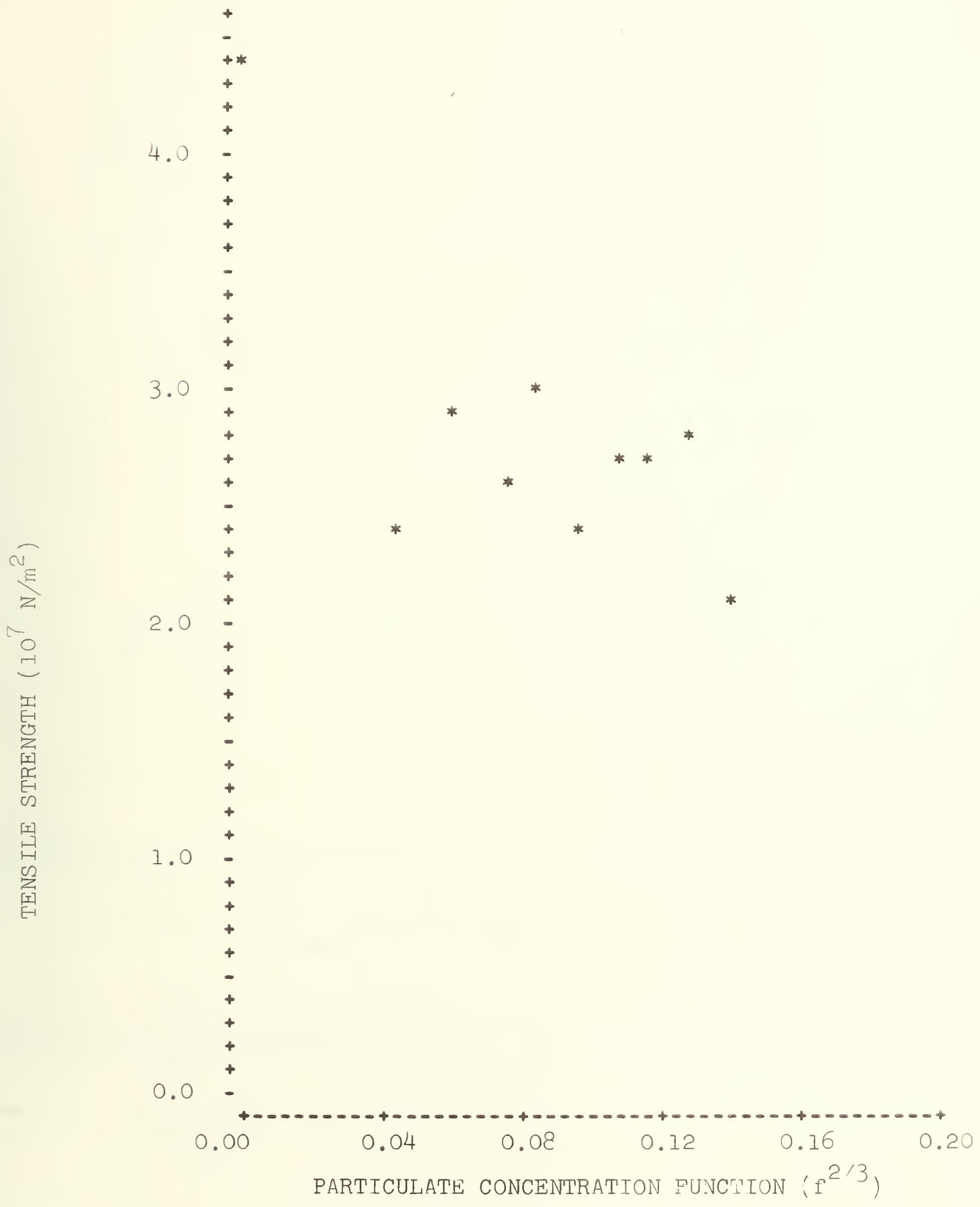

Fig. 7 : Tensile strength as a function of $\mathrm{f}^{2 / 3}$ for averages of replicate specimens of silane coupling agent (A-175) coated HA in Bis -GMA polymer.

(Polymerization initiated by a single 15-minute exposure to sun lamp 


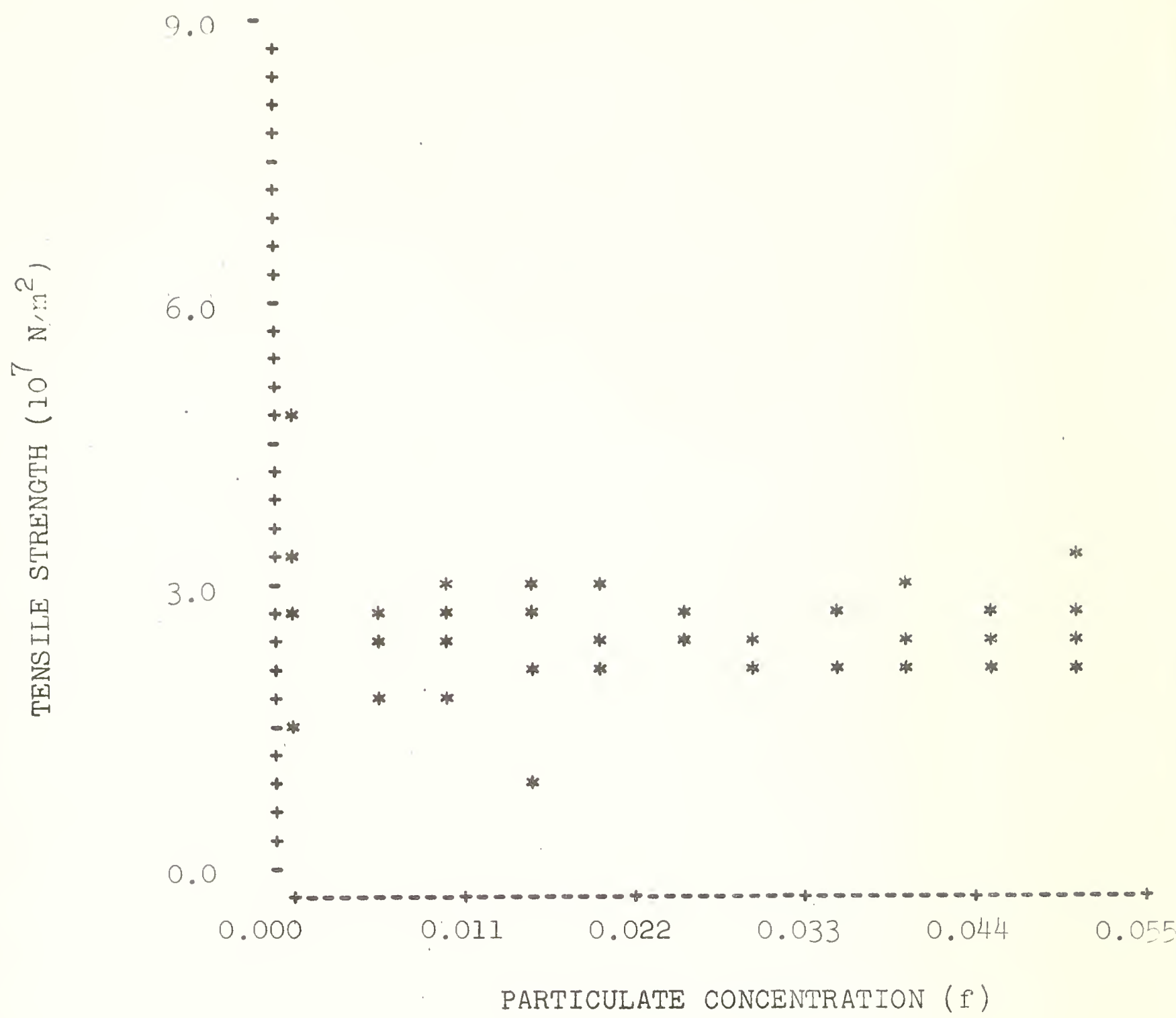

Fig. 8 : Tensile strength as a function of fraction ( $f^{\prime}$ ) of particulate plotted for individual points. Specimens consisted of HA precoated with four times the customary molar concentration of silane coupling agent $(A-175)$ in Bis-GMA polymer.

(Polymerization initiated by a single 15-minute exposure to sun lamp.) 


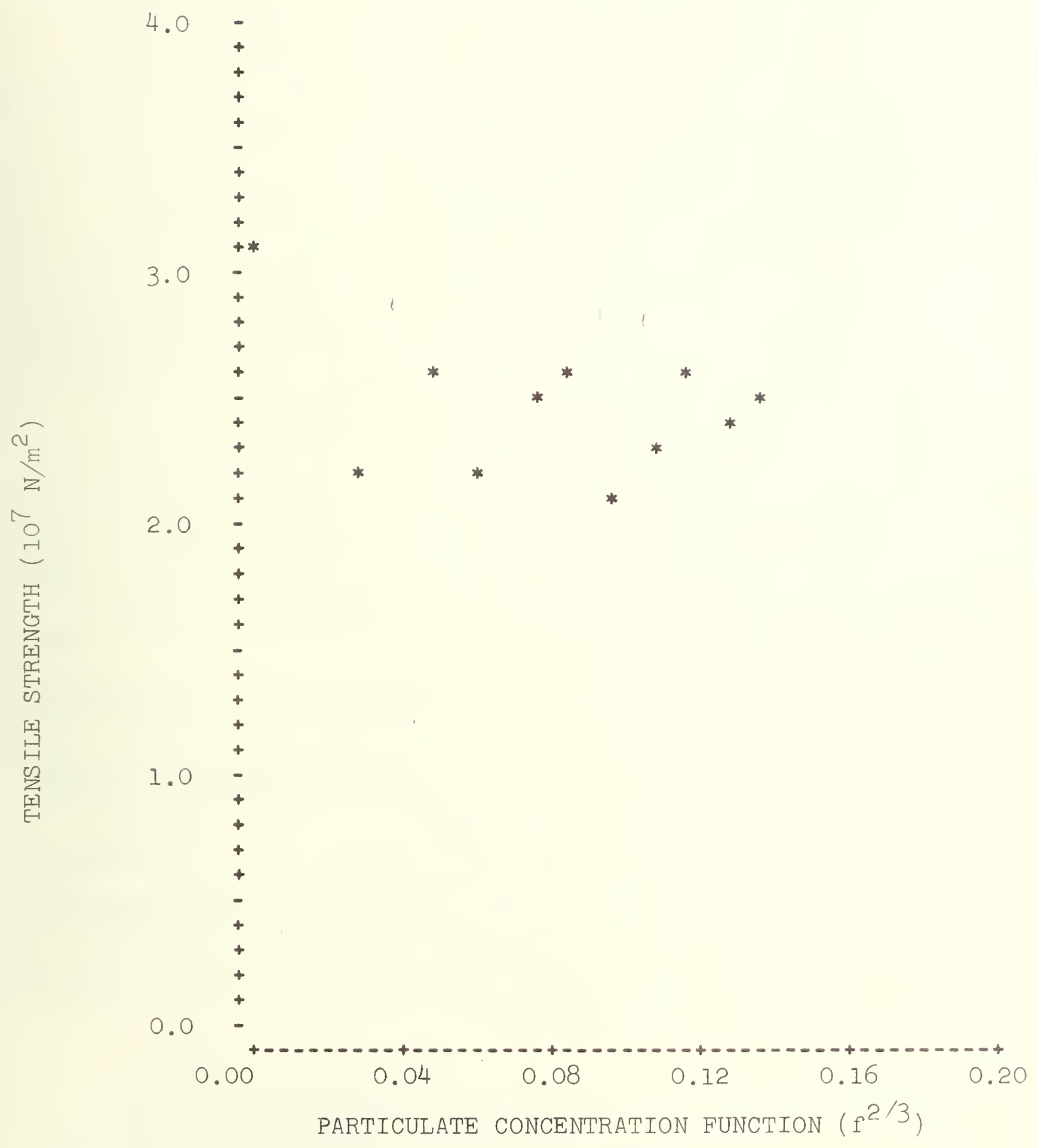

Fig. 9 : Tensile strength as a function of $\mathrm{f}^{2 / 3}$ for averages of replicate specimens of silane coupling agent (A-175) at four times the customary concentration coated on HA and polymerized with Bis -GMA. (Polymerization initiated by a single 15-minute exposure to sun lamp.) 
C. Synthesis for Improved Adhesion and Stability of

Composite Restorative and Sealant Materials

The currently most widely used monomer system, Bis-GMA, was $(4,5)$

developed by Dr. R. L. Bowen of this laboratory and represents a major achievement in this area of dental material research. However, in spite of its many excellent properties, it does suffer from several deficiencies, e.g. a color problem which may be inherent in its chemical structure or due to impurities, and a highly viscous nature which necessitates the use of a diluent comonomer. Since Bis-GMA is a complex mixture of high molecular weight optically isomeric dimethacrylates, purification by conventional techniques is difficult, if not impossible. The use of the thinner comonomer (e.g. methyl methacrylate) increases the polymerization shrinkage of the system. Due to the high volatility of methyl methacrylate, the commonly used Bis-GMA pit and fissure sealant material becomes increasingly viscous with use if care is not taken to seal the mixture promptly after each application.

To overcome these deficiencies of Bis-GMA, Dr. Bowen developed a novel monomer system based on the premise that certain relatively low melting isomeric solid monomers on proper admixture can form eutectics that are liquid at room temperature. The first attempt at this type of system involved aromatic diester dimethacrylates derived from the three isomeric phthalic acids . The low melting monomers were synthesized by the conventional condensation reaction below:

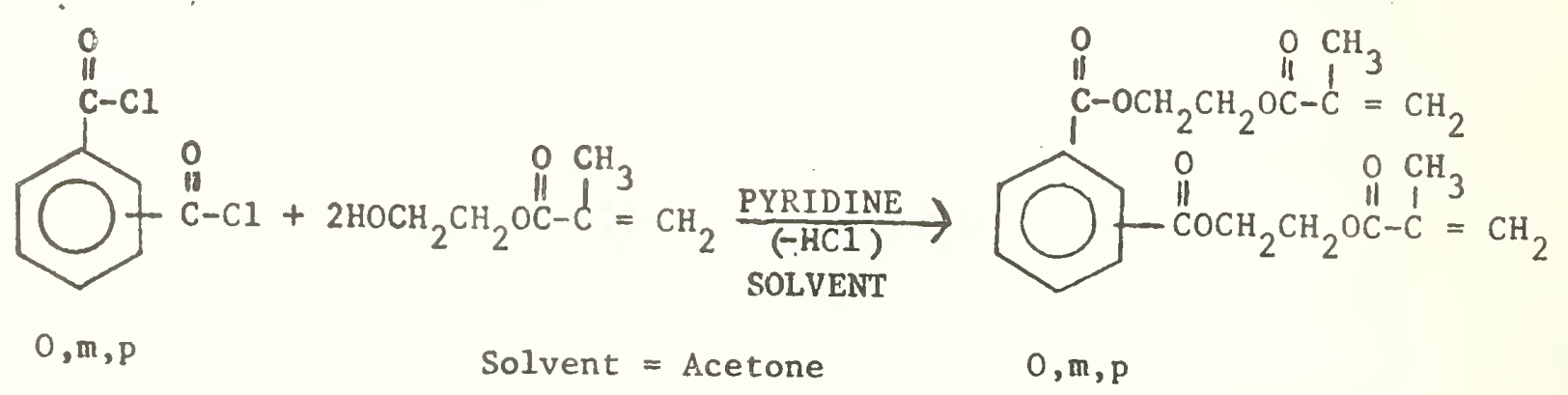


Since the individual monomers are crystalline solids, purification is easily effected by simple recrystallizátion techniques. Proper admixture of the three monomers (ortho, meta and para) results in a liquid ternary eutectic having a workable viscosity and low enough polymerization shrinkage for use as a resin binder for dental composites. (7-9) Unfortunately, a disturbing color instability was noted when the system was polymerized by the usual benzoyl peroxide-tertiary aromatic amine initiated system. This color problem was rraced co the formation of colored charge transfer complexes between the pi electron deficient aromatic diester dimethacrylates and the pi electron-rich tertiary aromatic amine accelerator.

$$
\text { In work reported previously, }(11,12) \text { we circumvented the colored }
$$

charge transfer complex problem by the synthesis of two analogous crystalline monomer systems that possess somewhat greater pi electron densities. One system is based on dimethacrylate derivatives of the isomeric dihydroxybenzenes (i.e. hydroquinone, resorcinol and catechol). The appropriate synthesis and structures are given below:

\section{Aromatic Ether-Ether Dimethacrylates}

$$
\text { SOLVET (Acetone, } \underbrace{\mathrm{CH}_{2} \mathrm{Cl}_{2}}_{2} \text {, etc.) }
$$


This system is currently being investigated for its potential as a field composite restorative material for the U. S. Army Dental Corps.

The second system is based on dimethacrylate derivatives of the three isomeric hydroxybenzoic acids. The methods of syntheses are illustrated below:

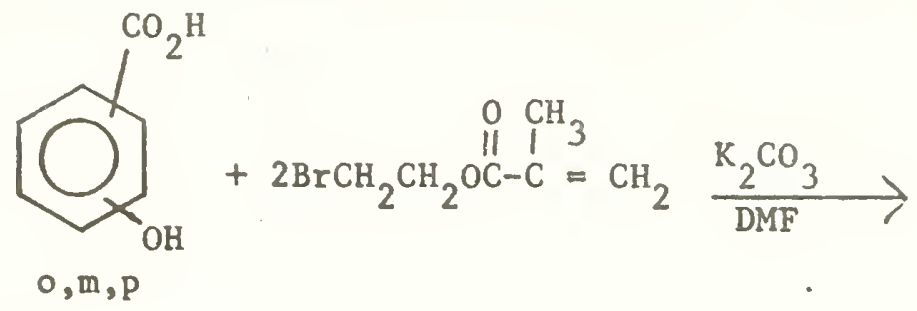

or
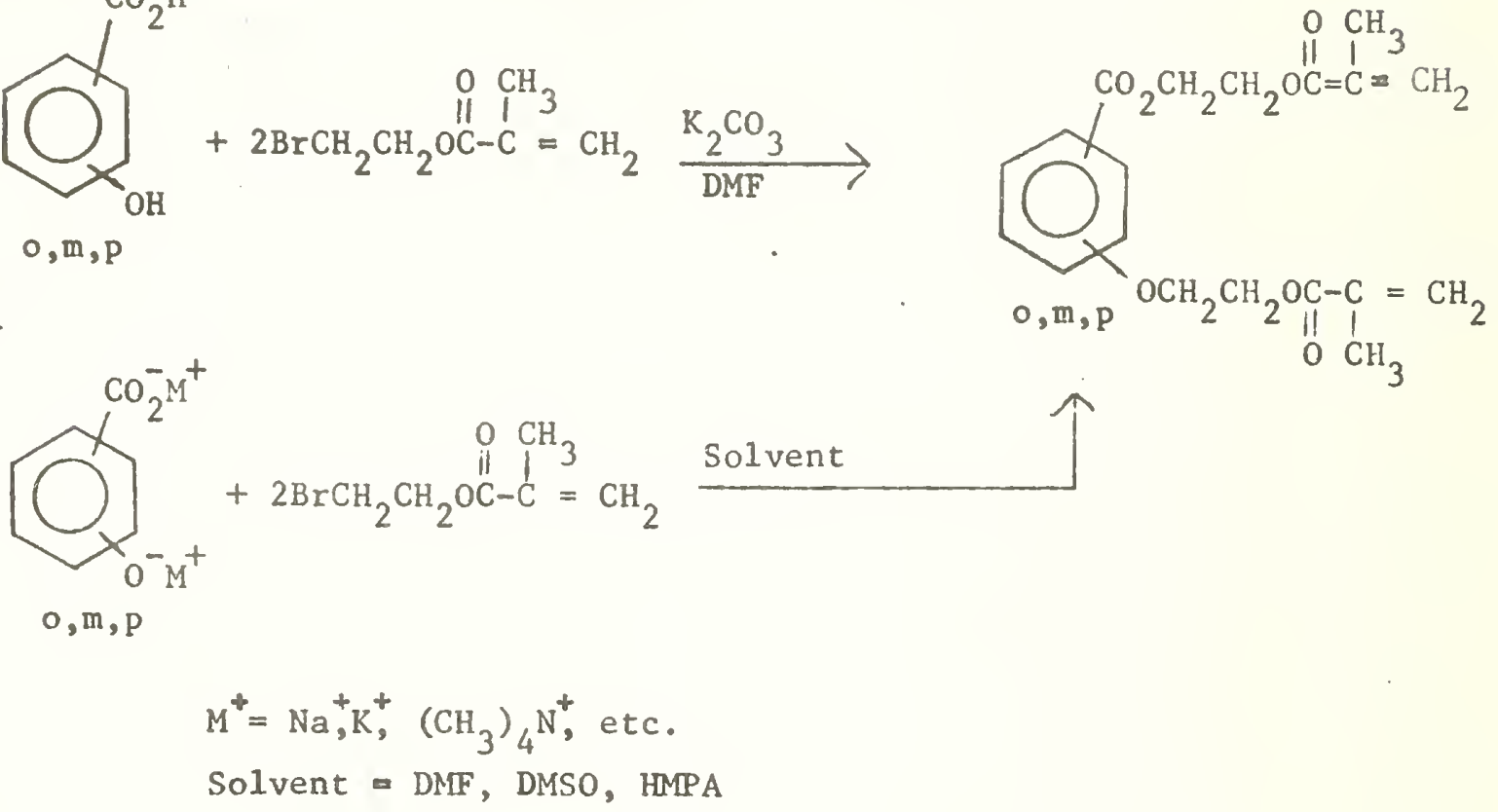

As predicted by theory, neither the aromatic diether dimethacrylates nor the aromatic ether-ester dimethacrylates form colored charge-transfer complexes with tertiary aromatic amines. In addition, both systems are easily purified by recrystallization and form, on proper admixture at room temperature, ternary liquid mixtures of moderate viscosities.

Unlike the preparation of the para and meta isomeric ether-ester dimethacrylates by the above methods, the synthesis of ortho isomer continues to present problems with regard to yield and, especially, ease of purification.

We are currently synthesizing the ortho isomer by the two alternate methods outlined as follows: 
(1)<smiles>O=C(O)c1ccccc1O</smiles>

$\mathrm{CH}_{3}$ $+\mathrm{HOCH}_{2} \mathrm{CH}_{2} \mathrm{OC}-\stackrel{\mathrm{I}}{\mathrm{C}}=\mathrm{CH}_{2}$

Catalyst

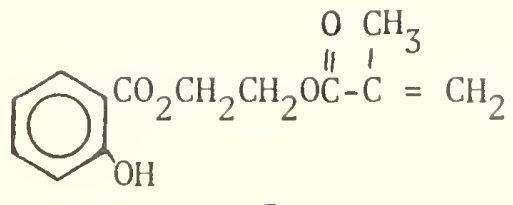

I<smiles>C=C(C)C(=O)CCOc1ccccc1C(=O)OCCC(=O)C(C)C</smiles>

I I

(2)

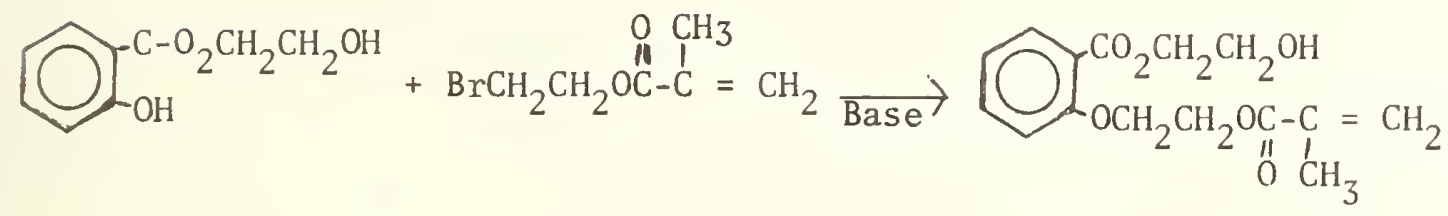

$$
\mathrm{III}+\mathrm{CH}_{2}=\stackrel{\mathrm{CH}_{3}}{\mathrm{C}} \stackrel{\text { II }}{\mathrm{C}}-\mathrm{Cl} \underset{\text { Base }}{\rightarrow} \text { II }
$$

In addition to providing an attractive route to the ortho etherester dimethacrylate (II), the intermediate, I, may have adhesion-promoting potential because of its phenolic group.

\section{Polymerization of New Monomer Systems}

Both the aromatic diether and ether-ester dimethacrylates undergo facile polymerization with the usual free radical techniques (e.g. benzoyl peroxide plus tertiary aromatic amine and photoinitiator, plus UV light) commonly employed in dentistry. The resulting polymers are clear hard resins comparable to those obtained from the Bis-GMA systems.

These new monomer systems, with already workable viscosities, would seem to offer advantages over the widely used Bis-GMA/methyl methacrylate (MMA) sealant system. A problem with this latter system is a gradual increase in viscosity with use due to loss of MMA through evaporation. The new monomer systems would not suffer from this deficiency since a11 the components are non-volatile. 
Monomers that have, in addition to their polymerizable vinyl groups, other functional groups in their chemical structure that are capable of reacting and/or interacting with enamel and/or dentin belong to a class of monomers termed functional, and as such should serve as adhesion-promoting agents for both restorative composite and sealant materials. For example, acrylic acid, because of its polar carboxylic group, is a monomer that is capable of reacting with enamel. In its polymeric form, polyacrylic acid, or as a suitable copolymer, it forms the basis of the polycarboxylate and iunomer glass cements.

Carboxylate and Phenolate

It would be highly desirable to have similar monomers that had pendant carboxylic groups, but that were considerably less hydrophilic than acrylic acid. Ideally, the functional monomer should possess (except for a polar end) a largely hydrophobic chemical structure. The polar tail (e.g. - $\mathrm{COOH}$ ) of the molecule should be able to displace moisture from the tooth surface and establish concomitantly, by chemical reactions or strong physical attraction, a hydrolytically resistant adhesive bond to the enamel substrate. Copolymerization of the functional monomer with resin monomer should form a largely hydrophobic interlayer between the tooth surface and the restorative composite or sealant.

Our initial attempt to synthesize such a monomer resulted in the high melting solid monomer, p-(2-methacryloxyethoxy) benzoic acid (a product of the reaction of p-hydroxybenzoic acid and 2-bromoethyl methacrylate). It was reasoned that the ortho isomer, o-(2-methacryloxyethoxy) benzoic acid, might be a more useful functional monomer since it would probably be lower melting and would have its ionic interaction capabilities augmented 
by a reinforcing complex formation of the type shown (IV):
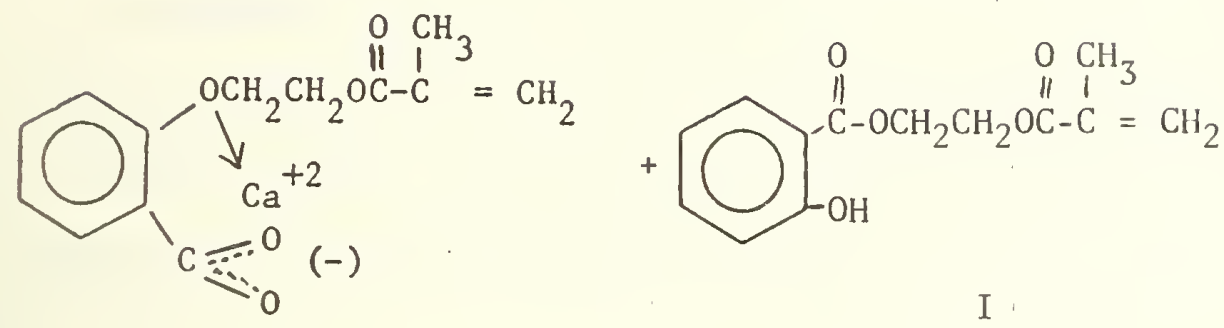

IV

However, initial preparation resulted in a complex mixture of products that includes I and IV. We have not been able to isolate the desired carboxylic monomer. A'modified synthesis for IV is under 'investigation. Monomer I is available from the synthesis plan described earlier in this section of the report.

\section{$\underline{\text { Aldehydes }}$}

A second type of functional methacrylate monomer is that represented by p-(2-methacryloxyethoxy) benzaldehyde, which we had previously prepared from p-hydroxybenzaldehyde and 2-bromoethylmethacrylate. This monomer is a solid, m.p. $47-8^{\circ} \mathrm{C}$, which can be polymerized by the usual free radical techniques. In this case, the functional or adhesion-promoting group is the pendant aldehyde group. Aldehydes are capable of reacting with collagenous substrates (e.g. the Schiff base reaction). In addition, aldehydes are relatively easily oxidized to carboxylic groups so that unreacted aldehyde groups are potentially capable of promoting adhesion to the mineral phase of tooth structure as well. A possible interaction with bone when the monomer was thermally polymerized on this substrate was indicated in our earlier work.

The ortho isomer, which we have now derived from salicylaldehyde and 2 -bromoethyl methacrylate, also is a solid, m.p. $52-3^{\circ} \mathrm{C}$. However, the 
meta isomer derived from the corresponding m-hydroxybenzaldehyde appears to melt near room temperature. Purification by recrystallization has been difficult in this case. From the three functional isomeric monomers, it should be possible to prepare a mixture of isomers that is liquid at room temperature, giving another potentially useful eutectic system of pure methacrylates for application in composite restorative systems or as sealants.

\section{Isocyanate}

Another type of functional monomer is that derived from the controlled reaction of hydroxyethyl methacrylate and 2,4-toluene diisocyanate. Taking advantage of the difference in reactivity of the two isocyanate groups (the NCO group para to the methyl group is more reactive) and the insolubility of the initial reaction product in $n$-hexane, we have prepared, in highly pure form, 4-(methacryloxyethyl)-2-isocyanotoluene urethane, a white crystalline solid, m.p. $66-68^{\circ} \mathrm{C}$. Infrared and NMR analyses confirm the assigned structure.

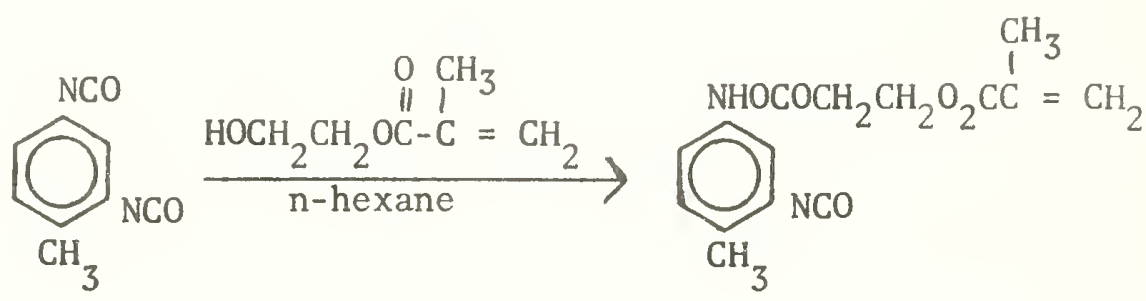

Similarly, we have prepared an analogous cycloaliphatic monomer, as shown:<smiles>CC1(CNC(=O)[O-])C[C@H]2C[C@](C)(CN2C(=O)[O-])C1</smiles><smiles>C=C(C)C(=O)OCC(C)CO</smiles><smiles>C=C(C)C(=O)CCC(=O)NC1(C)CC([N+](=O)[O-])CC(C)(C)C1</smiles> 
Monomers of these types should be capable of reacting with the collagenous component of dentin through active protoic sites (e.g. $\mathrm{NH}_{2}, \mathrm{OH}, \mathrm{CO}_{2} \mathrm{H}$ ) at or near the surface of dentin. The aromatic isocyanate containing urethane methacrylate undergoes facile free radical polymerization (chemical, photochemical and thermal) and has been successfully copolymerized with the aromatic diether dimethacrylate eutectic to give a tough clear copolymer. Both monomers formed copolymers with a Bis-GMA (diluted with triethylene glycol dimethacrylate) monomer system. In the case of Bis-GMA monomer systems, the presence of secondary $\mathrm{OH}$ sites in the resin may compete with the active sites in dentin for the available NCO groups. On the other hand, the $\mathrm{OH}$ groups of the Bis-GMA resin may serve as a sink for unreacted NCO groups and promote adhesive bonding of the resin to dentin.

The cycloaliphatic monomer is a somewhat viscous liquid. An attempt will be made to synthesize aliphatic monomers that are less viscous. Fluoride

A fourth type of functional monomer that we have been investigating is that represented by the polyfluoroaromatic monomer, 2-methacryloxyethoxypentafluorobenzene, derived from pentafluorophenol and 2-bromoethyl methacrylate. A polymer or copolymer of this monomer is functionally capable of gradually releasing small amounts of fluoride ion by displacement of covalently bonded fluorine with weak bases such as water. For example, a sample of the homopolymer was prepared, immersed in distilled water in a sealed polyethylene tube and the $\mathrm{F}^{-}$concentration determined periodically by means of a fluoride electrode. The $\mathrm{F}^{-}$concentration has shown about a fourfold increase in 10 weeks and an eightfold increase in 20 weeks, indicative of the potential anticariogenic character of this polymer. For each fluorine displaced by $\mathrm{H}_{2} \mathrm{O}$, a phenolic $\mathrm{OH}$ results in its place to give the new polymeric structure as shown: 

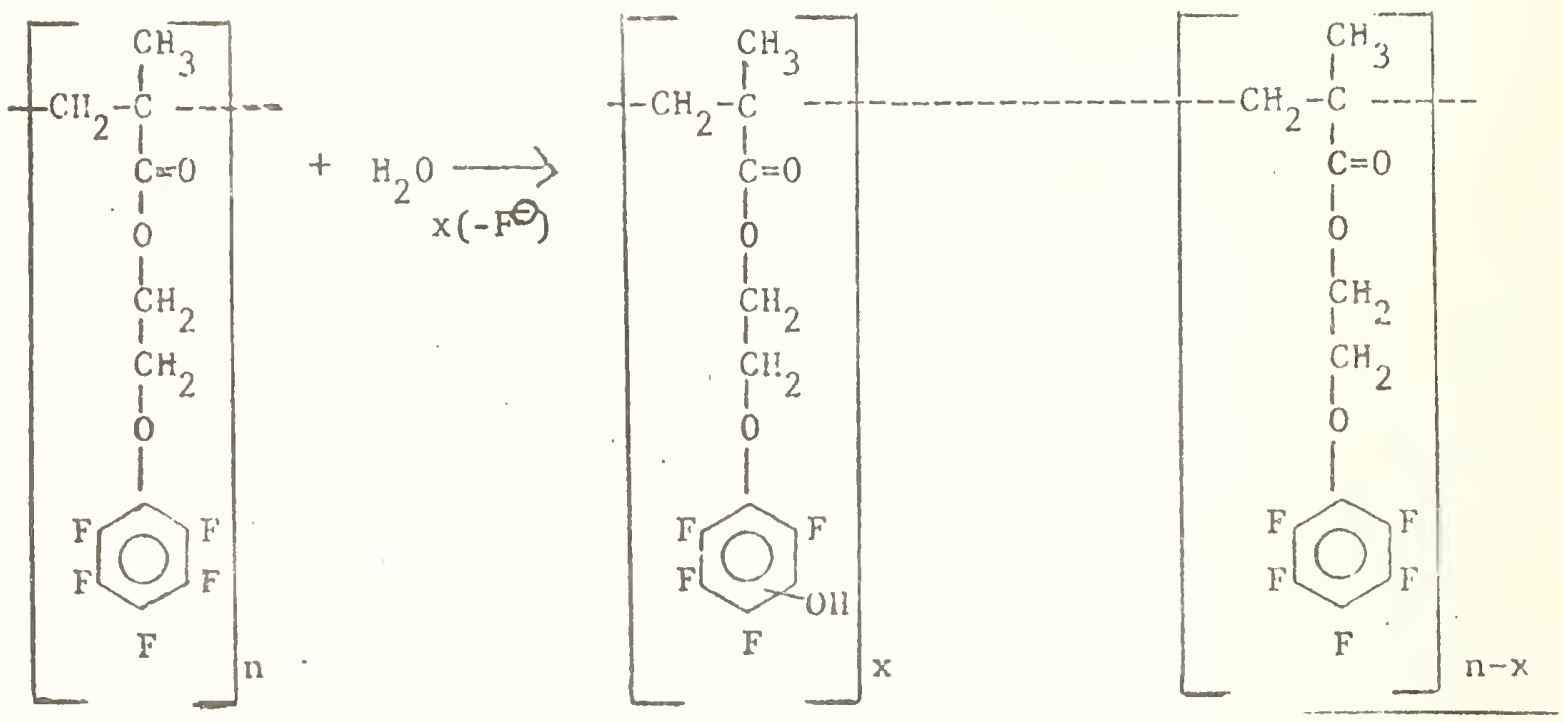

The presence of these phenolic OH groups, especially since their acidity is probably comparable to carboxylic groups, should promote adhesion to tooth structure via ionic interaction and hydrogen bonding.

The 2-methacryloxyethoxypentafluorobenzene (PFM) is readily miscible with Bis-GMA and serves as an excellent diluent for this viscous monomer. Two samples of copolymer of Bis-GMA and PFM have been prepared, one from chemical initiation (Benzoyi peroxide $+\mathrm{N}, \mathrm{N}$-dimethyl-p-toluidine), and a second from the photopolymerization (methyl ether of benzoin). Both polymer samples have been immersed in distilled $\mathrm{H}_{2} \mathrm{O}$ and their $\mathrm{F}^{\ominus}$ release is being monitored periodically by means of a fluoride electrode. The same gradual release of $\mathrm{F}^{\ominus}$ observed in the case of the PFM homopolymer appears to be occurring in the copolymer samples as well, although at a much slower rate.

Copolymerization for Hydrophobic 0leophobic Adhesives

Another type of functional comonomer capable of conferring a high degree of hydrophobicity (hydrolytic resistance) and oleophobicity (stain resistance) is represented by highly fluorinated aliphatic methacrylates (e.g. pentadecafluorooctyl methacrylate). Previously, we had reported the 
successful copolymerization of triethyleneglycol dimethacrylate containing benzoyl peroxide with pentadecafluoróoctyl methacrylate containing $\mathrm{N}, \mathrm{N}-$ dimethyl-p-toluidine. The two monomers are not very miscible, yet copolymerization occurs across the boundary phase. Not all the fluorinated monomer copolymerized, as determined by solubility studies. The same experiment was repeated using a 70-30 mixture of Bis-GMA/triethyleneglycol dimethacrylate. Again, significant amounts $(>50 \%)$ of the fluorinated monomer copolymerized to form a hydrophobic, oleophobic coating over the Bis-GMA monomer system. By using 2-PFM as the diluent for Bis-GMA, it may be possible to increase the interaction of the highly fluorinated aliphatic methacrylate across the hydrocarbon-fluorocarbon interface and thereby increase the degree of copolymerization. The benefits of potential $\mathrm{F}^{\Theta}$ release would also be present in this system.

Polyfunctional, Surface-Active Amine Polymerization Accelerators

The reaction product of $\mathrm{N}-\mathrm{phenylglycine}$ and glycidyl methacrylate, NPG-GMA, has been shown by Bowen in this laboratory to exhibit significant adhesion-promoting properties to tooth surfaces when used as a comonomer with the usual resin monomer systems employed in restorative and sealant applications. calcium ion is shown:

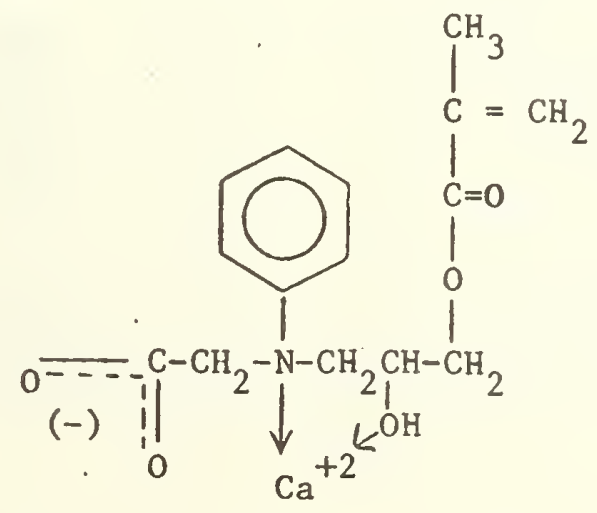


The mechanism of adhesion to enamel obtained by NPG-GMA involves chelation with complex formation of the surface calcium ions. Adhesion to the resin component of the composite is accomplished by virtue of the copolymerization reaction between the methacrylate groups of NPG-GMA and those of the resin monomer system.

The weak link in this type of adhesion probably resides in the strength of the chelation complex formed at the mineral interface. From purely statistical considerations, it would seem that adhesion to the enamel surface should be improved if the surface active agent had more than one chelating group per molecule. To test this hypothesis, we have synthesized a polyfunctional surface-active agent which is also an amine polymerization accelerator. The material is the reaction product of an epoxidized ortho cresol-formaldehyde novalac resin (molecular weight about 1270), N-phenylglycine and N-methyl-p-toluidine. On the average, the oligomeric molecule contains approximately 4 chelating groups for every 1.4 polymerization-accelerator groups. The structure of this novel surfaceactive agent is shown below:

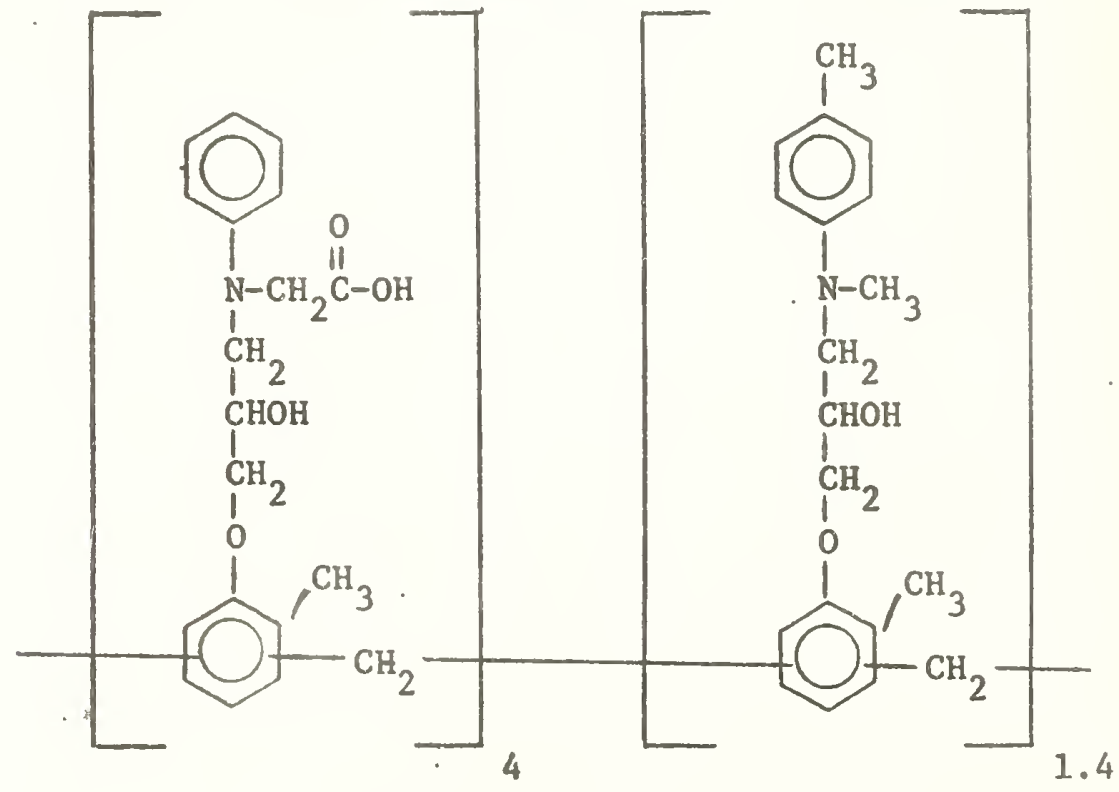


The oligomer not only has surface-active potential, but it has also the function of an accelerator for resin hardening. Although the molecular weight is over 2,000, the material is soluble in acetone and methylene chloride. Somewhat lower molecular weight oligomers are soluble in alcohol. The extremely large bulky nature of this surface-active agent should tend to minimize toxic side effects due to tissue penetration and volatility.

The room temperature polymerization of Bis-GMA monomer systems containing benzoyl peroxide in solution is readily accomplished by the accelerating effect of this material. In addition, it also initiates the polymerization of cyanoacrylate monomers.

The mechanism of bonding to the resin component of the composite may probably involve graft polymerization of some of the resin monomer from active radical sites created by the accelerator groups in the oligomer, radical coupling reactions involving oligomeric and polymeric radicals and, possibly, chain entanglements of the two polymers.

In an attempt to determine whether the oligomeric surface-active amine accelerator shown below can actually become covalently attached to a polymer, we have initiated a study of the polymerization of methyl methacrylate by benzoyl peroxide and this oligomeric accelerator. When the polymerization was conducted in a solution of $\mathrm{CH}_{2} \mathrm{Cl}_{2}$, some insoluble poly(methyl methacrylate), PMMA, mer formed which may suggest crosslinking of poly/through the oligomeric accelerator. When bulk polymerization was conducted, an insoluble gel was formed at about $30 \%$ conversion. These experiments suggest that the accelerator, to some extent, becomes attached to the PMMA. We plan to analyze these apparently insoluble polymers to determine if the attachment is indeed covalent. 
We will investigate preparation of an improved polyfunctional, surface-active amine polymerization accelerator with an acceptable color from N-p-tolylglycine, N-methyl-p-toluidine and the epoxidized orthocresol-formaldehyde novalac resin previously described. The starting $\mathrm{N}$-p-tolylglycine has been prepared by the condensation of p-toluidine and methyl chloroacetate.

Cyanoacrylates

We have initiated an investigation of cyanoacrylates as adhesionpromoting comonomers. Bis-GMA apparently initiates anionically the polymerization of both methyl and isobutyl cyanoacrylate. Presumably, the secondary $\mathrm{OH}$ groups of the monomer are responsible since alcohols (e.g. $\mathrm{CH}_{3} \mathrm{OH}$ ) are known to initiate the polymerization of cyanoacrylates. Surprisingly, the aromatic diether eutectic also spontaneously initiates the polymerization of cyanoacrylates. At present, we are not sure if this is an effect of the chemical structure of the monomer system, or due to a fortuitous catalytic impurity. No evidence of copolymer formation was found either with Bis-GMA or the ether eutectic. In contrast, the aromatic diester dimethacrylate eutectic (phthalate dimethacrylates) failed to initiate the anionic polymerization of the cyanoacrylates. A copolymer, however, could be formed by photochemical initiation using the methyl ether of benzoin. A similar result was obtained using isobutyl cyanoacrylate and triethyleneglycol dimethacrylate.

Attempts to form copolymers of isobutyl cyanoacrylate with a variety of comonomers by anionic initiation resulted in virtually $100 \%$ polycyanoacrylate. An exception appeared to be the case of maleimide and decafluorobenzophenone. For true anionic copolymerizations, the second monomer probably should have a vinyl group with a polar character approximating that of the cyanoacrylate. At the present time, free 
radical initiation, or a crossover type of free radical-anionic initiation, seems to be the best possibility for obtaining cyanoacrylate copolymers that may have utility as dental adhesives or liners.

\section{Improving Adhesion Through the Use of Low} or Near Zero Shrinkage Monomer Systems

The monomer Bis-GMA exhibits a low degree of polymerization shrinkage. However, because of its excessive viscosity, it has to be thinned with a diluent monomer of much lower molecular size, which increases the polymerization shrinkage of the monomer system.

We are exploring the possibility of using monomers of relatively large molecular size, but which can still function as effective diluents for Bis-GMA and other viscous monomers. One such system is based on the dimethacrylates derived from oligomeric primary diols of the type $\mathrm{HO}\left(-\mathrm{CH}_{2}-\right.$ $\left.\mathrm{CH}_{2} \mathrm{CH}_{2} \mathrm{CH}_{2}-0\right)_{\mathrm{n}} \mathrm{H}$. We have prepared two such dimethacrylates with molecular weights in excess of 1000 and 2000, respectively. They are low melting solids, but in their molten state, have viscosities less than that of BisGMA at the same temperature.

However, both the 2000 and $1000 \mathrm{M} . \mathrm{W}$. plus dimethacrylates, when used as diluents for Bis-GMA, did not reduce the latter's viscosity to a workable level. We are investigating the possibility of obtaining monomer systems with large molecular bulk and yet moderate viscosity through the use of highly branched or star-like monomers. A general synthesis of a star monomer is outlined below:

$$
\begin{aligned}
& 4 \mathrm{CH}_{2}=\stackrel{\mathrm{CH}_{3} \mathrm{O} h}{\mathrm{C}}-\mathrm{COCH}_{2} \mathrm{CH}_{2} \mathrm{O} \text { C }-\mathrm{NH}-\mathrm{R}-\mathrm{NCO}+\left(\mathrm{HOCH}_{2}\right)_{4} \mathrm{C} \\
& \downarrow \text { Solvent }
\end{aligned}
$$

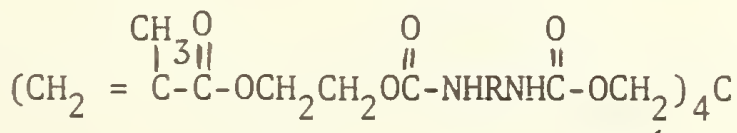

$$
\begin{aligned}
& \text { where } \mathrm{R}=\longrightarrow \mathrm{CH}_{3},{ }_{\mathrm{CH}}^{\mathrm{CH}_{2}} \underbrace{\mathrm{CH}_{3}}_{\mathrm{CH}_{3}} \text {, etc. }
\end{aligned}
$$


D. Techniques for Bonding to Mineralized

Collagen Surfaces

The lack of truly adhesive bonding of tooth surfaces to obtain a leakproof marginal seal, especially between dentin and restoration under oral conditions, is one of the main shortcomings of the restorative materials used presently in clinical dentistry. Possible ways to overcome this deficiency involve: (1) modification of tooth surfaces so that chelation or coordination with surface cations of the mineralized component (hydroxyapatite) of dentin can take place, or (2) by the reaction with the collagen component of dentin. The latter approach is being employed in the present investigation.

Present clinical procedures depend on mechanical interlocking for retention of restorative materials and thus require removal of non-carious tissue for the cavity preparation. Successful development of clinically applicable adhesive techniques for bonding to enamel or dentin surfaces would lead to simpler cavity preparations, resulting in decreased loss of non-carious tooth substance. Improved adhesion of acrylic resins to enamel can be obtained by acid etching pretreatment of the tooth surface which removes debris and opens up pores into which the uncured resin can flow. $(14-17)$ This increased adhesion is obtained after hardening of the resin because of mecharical interlocking of the resin at the enamel-resin interface.

However, etching pretreatment prior to the application of the presently used acrylic restoratives leaves the protein component of dentin substantially untouched. The presence of collagen at the dentin surface interferes with the mechanical adhesion of the inorganic constituent of dentin to organic adhesives. Thus, in contrast to its successful use with enamel, etching produces a bond between dentin and acrylic restorative resin that is too weak to withstand the forces encountered at the interface 
under clinical conditions.

The grafting of monomers to cóllagen of soft and hard tissues so that after polymerization of the monomer, the proteinaceous surface is bonded - usually covalently to the polymer side chain - offers an attractive technique for modifying collagenous surfaces, such as dentin, to a more adhesive compatible state. Thus, after the free radical polymerization (or anionic polymerization in the case of cyanoacrylates), the proteinaceous substrate surface is bonded covalently (or by ionic interaction) to the polymer side chain. With most acrylic or vinyl monomers, this reaction apparently proceeds with the amino or hydroxyl carbon as the preferred grafting site by the mechanisms shown schematically in Figure 1:

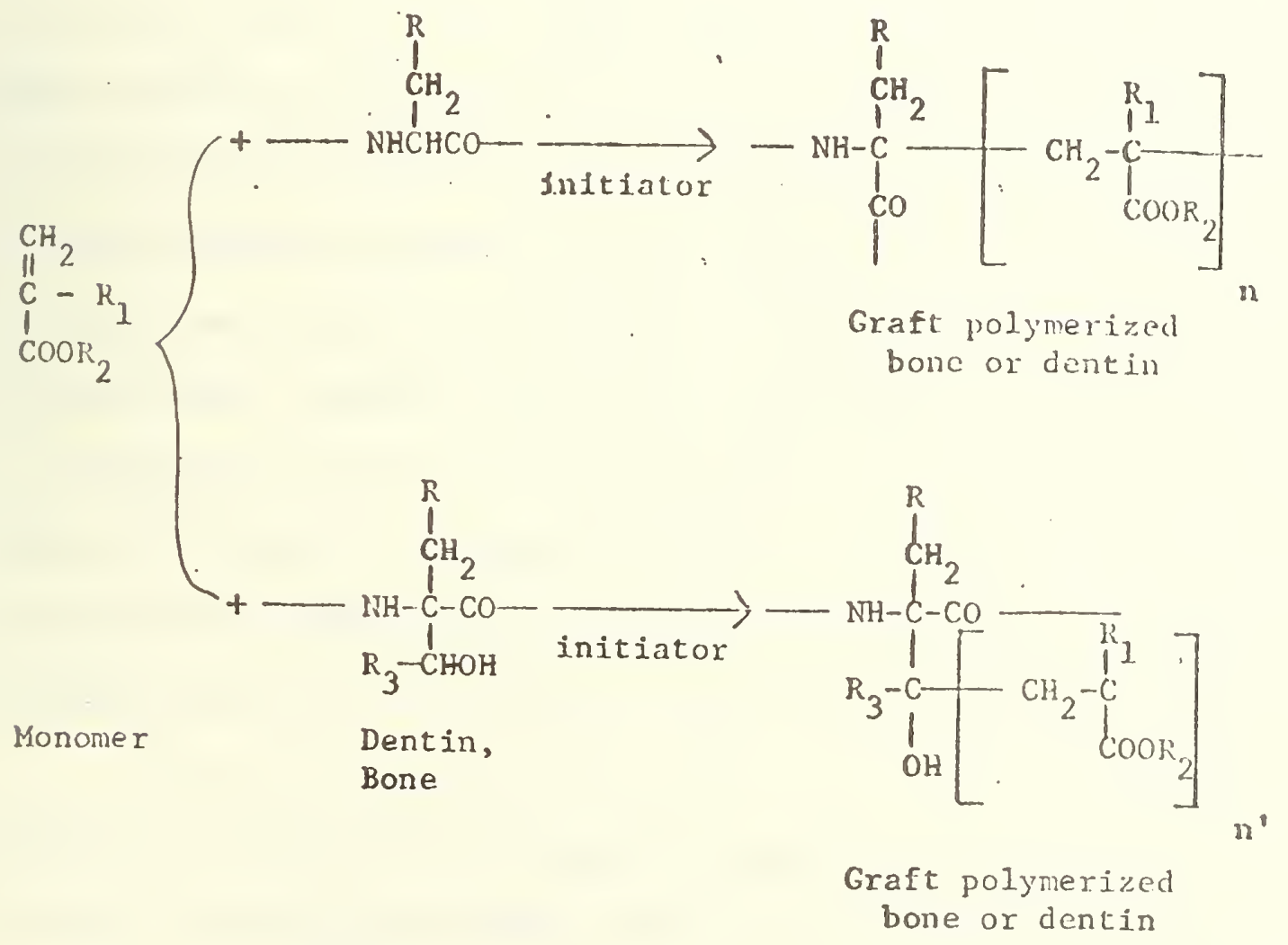

Figure 1 
In this laboratory we have shown the wide scope of the ceric ammonium nitrate initiated graft polymerization to steer hide collagen and soft tissues such as calfskin or ratskin. These reactions were conducted in an aqueous environment under conditions which, with suitable modifications, might be tolerated in vivo. $(18,19)$ over 30 monomeric acrylic and methacrylic esters, as well as other selected vinyl monomers of varying polarity, were demonstrated to be grafted to collagen.

In this present project, these investigations were extended to $(20-23)$

hard tissues. Bone was initially selected as substrate since it can be more readily obtained than dentin. Contrary to the large number of monomers that could be grafted to soft tissues, the ceric ion initiated grafting did not prove too successful with bone as substrate. Consistent grafting, as indicated by the increased weight of the substrate after removal of soluble homopolymer by suitable solvents, occurred only with a few polymers such as methyl or glycidyl methacrylate. Much more successful was the reaction of various monomers with bone, using as initiator the persulfate-bisulfite redox system. Properties of the "added" synthetic polymer can be readily imposed on the hard tissue surface. Depending on the monomer used, bone surfaces with properties desirable for specific applications can be obtained in a controlled manner. It was clearly shown that hydrophilic, hydrophobic and even oil-repellent surfaces can be prepared. Thus, the wettability and water sorption were greatly altered by this treatment.

In the persulfate-bisulfite initiated reaction of bone and methyl methacrylate or styrene, evidence for true grafting, as opposed to an interpenetrating mechanical attachment, was obtained. (24) Treated bone was demineralized and the hydrolyzed residue was extracted exhaustively 
with water and alcohol-water solutions. The presence of a positive ninhydrin test for the purified hydrolysis product of the treated bone shows that, at least for these reactions, a true graft is formed. After extended methanol extractions of the hydrolyzed product, a negative test was obtained which may be indicative that grafting occurs mainly with the formation of low molecular weight poly(methyl methacrylate), which is slightly soluble in methanol at the elevated temperature of the Soxhlet extraction. Grafting may also occur for higher molecular weight poly(methyl methacrylate); however, the ratio of amino acid end groups formed on hydrolysis to the number of recurring methyl methacrylate units is extremely small and cannot be detected by study of the infrared spectra or by color tests.

The formation of a true graft or of an interpenetrating network is likely to depend not only on the monomer, but also on experimental such parameters/as kind of initiator, reaction temperature and $\mathrm{pH}$. Thus, in controls with glycidyl methacrylate in the absence of bone, a soluble polymer was formed with ceric ammonium nitrate initiator, whereas an apparently crosslinked insoluble product was obtained with persulfatebisulfite. With the latter initiator, 2-cyanoethyl acrylate also yields an insoluble polymer. It is likely that with these and other bifunctional monomers, a separate, interpenetrating polymer phase entwined with macromolecules of the collagen may be formed in the persulfate-bisulfite initiated reaction.

Even if the substrate and polymer chains are not covalently bonded, the surface properties of the resulting product will differ from the original substrate. On formation of an interpenetrating network, an improvement in some properties such as the tensile strength may be obtained.

The persulfate-bisulfite initiated grafting of calcium or zinc 
acrylate with bone was pursued further. Substitution of zinc or calcium acetate for the respective acrylate salts in the reaction gave no increase in weight for the treated bone. Thus, the increase in weight of the acrylate-treated bone is not the result of adsorption of zinc or calcium ions. A graft of the calcium-containing monomer to mineralized bone or dentin may present the possibility of incorporating calcium in defective or damaged tissues.

To obtain more nearly instantaneous grafting, we investigated UVinitiated reactions. Using the ethyl ether of benzoin or riboflavin as UV initiator, usually in $2 \%$ concentration, various monomers were subjected to a commercial UV light source which emits light mainly near $360 \mathrm{~nm}$. Acrylic or methacrylic monomers, even those containing functional groups and freed of inhibitor, did not cure within $3 \mathrm{~min}$. unless an aromatic monomer such as the adduct of bisphenol $\mathrm{A}$ and glycidyl methacrylate was present. Addition of a photocrosslinking agent (1-aza-5-acryloxymethyl-3,7-dioxabicyclo $[2,2,0]$ octane) did speed up the polymerization, especially with glycidyl methacrylate. However, no apparent adhesion to flat unetched bone or unetched bovine enamel or dentin was observed for any of these formulations.

These results indicated that any system using UV initiation is likely to require ingredients which induce rapid polymerization, as well as constituents which before, during or after polymerization, react or interact with the hard tissue surface. With the aim of developing efficient U.V.-curing formulations that also serve as vehicles for copolymerizable components with functional groups (e.g. isocyanate) that can react with, and thus can be grafted to, hard tissues, the following approach has been taken. Various formulations containing Bis-GMA, eight different 
monomer diluents and concentrations of UV initiators were prepared and their curing characteristics studied.'A nearly complete cure, except at the surface, was usually obtained in less than 1 minute. For adhesive formulations, a somewhat thicker mix may be preferable to minimize shrinkage on curing. On storage in water, thin films, even those containing higher molecular weight acrylates such as ethylhexyl acrylate or 2,2,2trifluoroethyl methacrylate, increased in weight initially, but lost weight for many weeks thereafter. This decrease was generally larger than the initial gain resulting from water sorption. This leaching out of residual monomer (which apparently is larger for higher molecular weight acrylates or methacrylates due to incomplete polymerization) and other components of a potential liner is likely to result in stresses which ultimately will lower adhesion between this material and the hard tissue surface. To minimize the leaching out of constituents on storage in water, $3 \%$ to $5 \%$ of a monomer, 1-aza-5-acryloxymethyl-3,7-dioxabicyclo $[2,2,0]$ octane was added to the formulation. This monomer exhibits free radical/photochemical reactivity which not only enhances the cure rate, but also produces photocrosslinking. (26) These cured films had lower water solubility and are being further evaluated in long term studies.

Chemical groups which probably react most readily with proteinaceous surfaces and which may be incorporated into some of the UV curable formulations are the isocyanate and 2-cyano/groups. Work has been initiated to study the grafting of 2-cyanoacrylates and urethanes containing free isocyanate groups to hard tissues. Kulkarni, et al! showed that, in the presence of glycine and methyl glycine, 2-cyanoacrylates polymerize by an anionic mechanism. The products contain amino acid residues. Thus, grafting of cyanoacrylates to proteinaceous surfaces is predicted. Our initial 
aim was to study the reaction with various substrates and to determine the hydrolytic stability of the bond formed. Whereas the lower homologues (methyl and isobutyl-2-cyanoacrylate) cure rapidly on collagen and skin, a small drop of commercial methyl-2-cyanoacrylate placed on bone or dentin surfaces does not cure within 5 minutes. Even pretreatment by swabbing of the surfaces with aq. or alcoholic solutions of mild initiators for anionic polymerization such as alcohols (including hydroxyethyl methacrylate and Bis-GMA), ethylenediamine tetraacetic acid (EDTA) buffered to pH 9.3 or diammonium hydrogen phosphate, did not speed up the curing sufficiently. However, use of a $10 \%$ aq. solution of the tetrasodium salt of EDTA, a $50 \%$ alcoholic solution of tert. butylaminoethyl methacrylate or 1 to $10 \%$ alc. solutions of dimethyl-p-toluidine yielded hardening times ranging from 15 $\mathrm{sec}$. to $1 \mathrm{~min}$. On storage in water at room temperature, thin films of the cyanoacrylate did not peel off from the bone surfaces. We have investigated the bonding of a methyl-2-cyanoacrylate liner between dentin and a composite resin using the tensile adhesion test of Lee, Swartz and Culp. (28) The tensile adhesion values for bovine dentin specimens pretreated with $1 \%$ alcoholic dimethyl-p-toluidine and various etching techiques such as swabbing for $30 \mathrm{sec}$. with $0.1 \mathrm{M}$ EDTA buffered to $\mathrm{pH}=9.3$ were considerably lower than adhesion values for cyanoacrylates reported in the $(29-31)$ literature. Etching of dentin with EDTA solutions increased adhesion only marginally. Although there were differences in the cyanoacrylates used in this and the previous studies, the main reason for this discrepancy of the tensile adhesion values of the in vitro investigations $(29,30)$ and ours appears to be differences in experimental procedures. In our study, the cyanoacrylate liner was placed on the dentin and uncured resin (Adaptic) inside a cylinder was positioned on top; whereas, in the previous experiments, 
a cured (flat) plastic cylinder was used. We believe that our experiments more nearly simulate clinical conditions to which a liner is subjected; that is, stresses are set up (due to the $2 \%$ curing shrinkage of the composite material) which weaken the bond.

The key step in the successful application of a cyanoacrylate is the formation of a thin adhesive film between two well-mated surfaces. The thinner the film, the faster the rate of bond formation and the higher the ultimate bond strength. For the adhesive to form a permanent bond between hard tissue and restorative resin, the two mating surfaces must fit together closely without gaps or voids since these adhesives have no gap-filling capability. Because of the curing shrinkage of dental restoratives, it appears unlikely that the pure cyanoacrylates, without thickening agents, plasticizers or other modifying agents which would give the material more body, can be useful as liners for dental restoratives that cure in situ. For sealant applications, the lack of gap filling ability is less important.

For measuring the adhesion of cyanoacrylates to bone, we have adapted the following procedure. A large number of bone cylinders with a diameter of $0.8 \mathrm{~cm}$ were machined from marrow bone. Great care is taken to prepare specimens with completely flat surfaces. The flat surfaces are joined together by the potential adhesives, using a carefully standardized technique. The specimens were then stored in water for desired periods. By means of approximately $0.4 \mathrm{~mm}$ grooves in the cylinders, the specimens are held in grips which can be attached to the Universal Testing Machine so that after alignment, a vertical load is applied to break the joint. A loading rate of $0.2 \mathrm{in} / \mathrm{min}$ (approximately $5 \mathrm{~mm} / \mathrm{min}$ ) is used.

An advantage of this screening test for adhesives is that the hard bone tissue does not have to be embedded in a resin matrix - a timeconsuming procedure. Furthermore, the bone cylinder can be resurfaced and 
re-used.

Our initial objective has been to determine the effect of various factors such as degree of surface smoothness, extent to which the bone has dried and length of storage of the joined specimens in $100 \% \mathrm{RH}$ at $37^{\circ} \mathrm{C}$ prior to their immersion in water. We find that for some of these factors, no statistically significant effect was obtained. This may be largely due to the relatively high coefficient of variation (often 30 to $40 \%$ ) which is generally encountered in tensile adhesion measurements that involve biosurfaces.

Results of some of the determinations are given in Table 1. Compared to commercial dental composites or a dental resin bonding system used after acid etching of the bone surface, the monomers containing 2cyanoacrylate or isocyanate groups yielded much higher bond strength values without any pretreatment of the bone surface. Thus far, fairly high, reproducible bond strengths have been obtained with a commercial material (Alpha Ace CN-4) even after changing a number of experimental parameters. Isobutylcyanoacrylate, which is considered to be less toxic than the lower homologues of the 2-cyanoacrylate series, also gave adequate adhesion, but the bond strength values had a higher coefficient of variation than was obtained with the commercial material. A viscous isoamylcyanoacrylate obtained from the Army Medical Research and Development Laboratory at Fort Detrick, Md. gave the highest bond strength of the materials studied so far. Maximum tensile adhesion values obtained ranged up to $7.9 \mathrm{MPa}$ (1100 PSI). For this material, the average bond strength is actually considerably higher than the value given in Table 1 since a number of specimens broke in the bone and not at or within the joint. Efforts will be made to improve the design and the technique of preparing the bone cylinders so that 
bond strength above $5 \mathrm{MPa}$ (700 PSI) can be accurately determined. 'The isocyanato group also improves bonding 'to bone. Thus, a 3-isocyanatomethyl-3,5,5trimethylcyclohexyl isocyanate-2-hydroxyethylmethacrylate (IDPI-HEMA) adduct was prepared in this laboratory. It contains one isocyanate group and one urethane group besides the methacrylate group. On application of a mix containing this adduct $(1 \mathrm{~g}), 0.1 \mathrm{ml}$ methyl methacrylate $0.01 \mathrm{~g}$ benzoyl peroxide and $0.005 \mathrm{~g}$ dimethyl-p-toluidine to bone, a joint was obtained which had a bond strength of $2.5 \mathrm{MPa}$. Because of the viscous nature of the mix, it is likely that such a mix may be an efficient adhesive where there is a gap between the two adherents.

Only preliminary work has been done on pretreating the bone prior to application of a resin. Only modest adhesion was obtained on treating bone with "Polysam" or the adduct of toluene diisocyanate and hydroxyethy1methacrylate prior to application of a commercial dental enamel bonding resin without using a pre-etch. Considerably better adhesion was sometimes obtained by bone pretreatment with the $\mathrm{N}$-phenylglycine-glycidyl methacrylate adduct (NPG-GMA), but the measured joint strengths varied greatly.

A study was made to determine if monomers containing the 2-cyanoacrylates or isocyanate groups are grafted, that is, bonded covalently, to bone. Bone specimens were primed with a $1 \%$ solution of dimethyl-ptoluidine and an ethylcyanoacrylate was spread on the treated bone. Attenuated total reflectance infrared measurements showed the presence of the 2-cyanoacrylate on the coated surface. This coating was not removed on prolonged water exposure. However, after placing the treated bone in acetone and dimethylsulfoxide with stirring and after removal of the solvent, the infrared spectrum again became identical to that of the 
untreated bone. Thus, contrary to the reaction which can be demonstrated with aminoacids, the collagenous component of the bone surface does not appear to bond covalently to 2 -cyanoacrylates. This is probably due to the limited number of active collagen sites present at the surface of the mineralized tissue.

The IDPI-HEMA liquid containing $2 \%$ methyl ether of benzoin, when placed on bone surface cured within 30 seconds after exposure to the NuvaLight UV source. The coating, after removal of some uncured material at the coating-air interface, adhered to bone specimens stored in water during the period of observation ( 2 months). The treated bone surface gave an ATR infrared spectrum that indicated the presence of isocyanate and methacrylate groups. Extraction of the bone with acetone and dimethylsulfoxide for 1 week did not change the infrared spectrum. Since the film obtained on curing IDPI-HEMA is not soluble in any of a number of common solvents studied, it is not possible to state if the IDPI-HEMA film is bonded covalently to bone or if the attachment to this substrate occurs by formation of an interpenetrating network.

Further studies are now underway to determine (1) which monomers containing 2-cyanoacrylate or isocyanate groups adhere to bone, (2) what surface pretreatments of the substrate, if any, are desirable to improve curing and efficiency of bonding, (3) what is the long-term hydrolytic stability of the resulting bond, (4) procedures for optimizing adhesion as a function of residual isocyanate groups or length of aliphatic group of 2-cyanoacrylate, (5) formulations for cyanoacrylate or isocyanate composites that could be used as adhesive gap fillers. Characterization of the substrate surface as fully as possible, using ATR-infrared, contact angle measurements and, if available, $x$-ray photoelectron spectroscopy is planned. 


\section{Tensile Strength of Various Adhesives to Bone}

Specimens stored in water for $24 \mathrm{hrs}$. at $37^{\circ} \mathrm{C}$.

Number of Tensile Adhesion, $\mathrm{MPa}$

Material

Specimens

S.D. (b)

Composite (Adaptic)

Concise Bonding Resin with etching

2-Cyanoacrylates

Eastman 910-EA

Loctite - EA

Cyanodent - Slow

Alpha-Ace

isoButy1cyanoacrylate

isoButyl cyanoacrylate (on dry bone)

Ethylcellosolve -

cyanoacrylate

Viscous isoamylcyanoacrylate

3-Isocyanatomethyl-3, 5,5-trimethylcyclohexylisocyanate-HEMA $+\mathrm{Bz}_{2} \mathrm{O}_{2}+$ DMPT

Dentin - NPG-GMA - Filling Resin

Etched enamel - composite
5

$0.02 \pm 0.06$

5

$0.06 \pm 0.12$

10

$0.95 \pm 0.26$

5

$1.45 \pm 0.61$

9

$1.82 \pm 0.75$

25

$3.48 \pm 1.02$

42

$2.73 \pm 1.47$ (a)

5

$0.02 \pm 0.06$

5

$0.08 \pm 0.16$

11

$4.61 \pm 1.48 \mathrm{MPa}$

10

$2.52 \pm 0.67$

(c)

$\sim 1.5$

(c)

6.9

(a) Mean value of all measurements of the bond strength conducted under varying experimental conditions.

(b) Standard deviation.

(c) Literature values. 
II. Physical Properties of Har $₫$ Tissue and Dental Materials

A. Dimensional Change Measurements

Dimensional changes of materials play a major role in the serviceability or lack of serviceability of most types of dental restorations. The initial accuracy of a tooth restoration usually depends upon dimensional changes which accompany the hardening of a restorative material whether the material is a polymer, an inorganic cement, a plastic alloy or a casting alloy. Usually, the dimensional changes that are significant are those that occur after the restorative material has become relatively rigid. These may be the result of continuing reactions as in amalgam or of thermal contraction as in the cooling of a casting alloy from its solidification temperature or cooling of a polymer from the temperature at which rapid polymerization has occurred. Maintenance of dimensional accuracy depends upon a similarity of thermal expansion of tooth and restorative material over the temperature range of approximately $50^{\circ} \mathrm{C}$ which commonly occurs in the mouth, and on the absence of other significant dimensional changes resulting from such phenomena as water sorption. The probability of maintaining adhesion between tooth structure and restorative material is reduced unless dimensional accuracy is maintained. It is evident that dimensional changes accompanying hardening and those resulting from temperature changes must be evaluated if optimum properties are to be obtained in restorative materials.

Dimensional changes which occur when a material is carried through a heating and cooling cycle may also be valuable indicators of reactions of one type or another that are taking place in the material. Thus, results previously reported for this project showed that the temperaturetime dependent dimensional changes of human dentin were related to delayed water loss on heating (in water) and water uptake on cooling. Information 
related to reactions in dental amalgam has been obtained from recent measurements of the thermal expansion of amalgam.

Measurements of the thermally induced dimensional changes of dental amalgams were made as one phase of a study of the factors which can be correlated with marginal failure of amalgam restorations. It has been shown by other investigators that failures are associated with high creep. Other investigations in this laboratory have shown that both creep and thermal expansion of amalgam alloys are related to mercury content. Figure 10 shows "thermal expansion" curves obtained for amalgams made from three different alloys, a lathe cut alloy, a copper dispersion alloy and a spherical alloy. When heating is started, all of the alloys show an initial straight line curve corresponding to a "normal"coefficient of linear expansion of about $25 \times 10^{-6} \mathrm{per}{ }^{\circ} \mathrm{C}$. For the conventional lathe cut amalgam, the straight line continues up to about $75^{\circ} \mathrm{C}$, where a sharp shrinkage occurs. Both of the other amalgams show this shrinkage near $75^{\circ} \mathrm{C}$, but in the copper dispersion amalgam, a rapid increase in expansion occurs below this temperature, while in the spherical amalgam a decrease in expansion has occurred. In these non-equilibrium curves (run at a rate of temperature change of about $0.4^{\circ} \mathrm{C} / \mathrm{min}$ ), two of the amalgams show continued expansion as they are heated from 75 to $85^{\circ} \mathrm{C}$ and then cooled from this temperature, while the spherical amalgam shows shrinkage through this temperature range. Both the conventional and the spherical amalgams show a large expansion at near $50^{\circ} \mathrm{C}$ on cooling, but this is not observed in the copper dispersion amalgam. It is evident that phase changes in these alloys are producing dimensional changes and either the phases, the relative amounts of the different phases, or the rates of change are different in the different amalgams. The dimensional change measurements clearly point out an area requiring further investigation by other means if an understanding of the reactions occurring in the 
amalgams is to be obtained. This work is being continued to include thermal expansion measurements on some of the new high copper content alloys designed to have low creep and reduced marginal failure relative to alloys with conventional compositions.

A large number of measurements of dimensional changes of investments for base metal casting alloys have been made and are reported under the discussion of the base metal casting alloy project later in this report. 


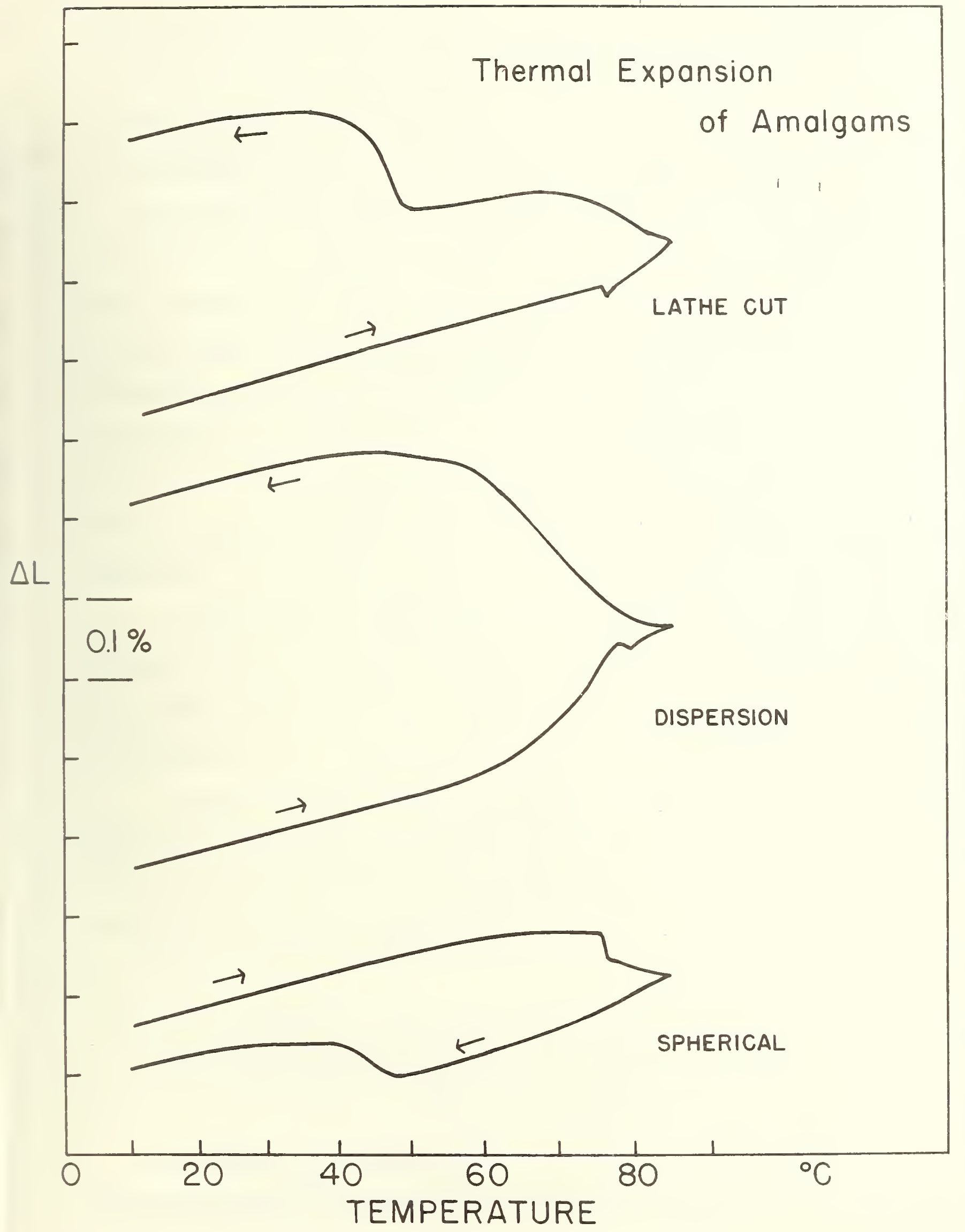

Fig. 10 
B. Wear Resistance of Restorative Materials

Adequate resistance to wear caused by normal masticatory function is a crucial property for materials placed on occlusal tooth surfaces where stress is imposed. Extensive funds and manpower are presently expended toward improvement of this specific property in composite type dental restorative materials.

Long-range clinical studies have shown most other properties of these materials to equal the best offered by amalgam alloys, particularly that of marginal integrity. Once sufficiently developed wear properties are attained, the aesthetic superiority of composites will make them the material of choice for most direct restorative applications.

Historically, the development of a reliable in vitro wear test has proved to be an elusive target. This has been particularly true when attempts were made to compare the wear resistance of various types of materials such as amalgam alloy and composite or non-metallic direct restorative materials. The primary objective of this project has been to design and develop such a test capable of providing clinically realistic wear data. The philosophy of the investigation has been the closest possible simulation of wear-related characteristics of hunan masticatory conditions to such an extent that the in vitro wear data will be similar to that observed clinically, while reducing the time and expense required for clinical evaluation.

Background covering design, construction, test method, material preparation, preliminary results and extensive modifications are all well-documented in the 1975 Annual Report.

All data collected thus far on an amalgam and a composite restorative material substantiate the theory upon which the wear-generating 
portion of the testing device was designed and constructed. Failure of the data acquisition and control system to record data consistently and to maintain proper measurement point trigger position was the cause of extensive modifications to these peripherals. Both of these problems stem from the very limited program capacity inherent in the outdated H.P. 2570A coupler-controller. Specifically, this instrument deficiency is responsible for unproductive running time for the testing device, waste of enamel wear heads which are difficult and expensive to replace, and, perhaps more importantly, measurements based on a marginal $90 \%$ level of confidence. As the non-metallic or composite restorative materials are enhanced by increased wear resistance, it is imperative that testing capability become more precise. Wear data taken at 95-99\% confidence level will be more appropriate.

Communication with the manufacturer of the 2570-A System in an attempt to update the unit proved fruitless since the company now considers this coupler-controller obsolete. All program expander options have been discontinued.

Many alternative methods were attempted to circumvent the limited program space in the unit, including both internal and external modification, as well as independent event timing devices. The precise sequencing necessary to make reliable measurements, however, proved to be too exacting for anything but direct program control. It was concluded at that point that the 2570-A System with its components had been taken as far as possible in an attempt to stabilize and perfect data output, and that it would be necessary to design and assemble a new control and data acquisition system.

Experience with the prototype wear generator has reinforced the opinion of materials manufacturers, and individuals involved in composite 
material development at this facility, that it would be highly advantageous to test several specimens at the same time. Drawings have been prepared for a multiple specimen testing device using the same design characteristics as those of the prototype device. The instrument incorporates three turntables, each with its associated measuring system. Design improvements include super precision ABEC-7 series bearing systems, greater horizontal rigidity in slider carrier arms and a direct gear drive to all turntables so aligned as to use gear thrust to maintain bearing seating force. A design modification in the parallel beam measuring system places the linear variable differential transformers directly over the measured points on the specimen. This feature allows the LVDT's to be calibrated off the device by a highly accurate expanded scale micrometer, providing more precise wear track depth measurements than were available from the prototype.

The new instrument is under construction in the NBS main shop and is approximate 1 y $90 \%$ complete.

An automatic control and data monitoring system developed specifically for NBS 1 aboratory application has been ordered to replace the borrowed H.P. 2570-A Coupler-Controller. Specifics concerning this new system are available in NBS Technical Note 790 "MIDAS Modular Interactive Data Acquisition System Description and Specification", August 1973, Superintendent of Documents \#C13.46:790.

Also on order to provide large capacity high speed data recording and storage, is a Texas Instrument ASR 733 Dual Cassette 30 c.p.s. terminal. This will be linked directly to an 0livetti P-652 Programmable Calculator (on loan from the U. S. Navy) through a BEDD ASCII-IPSO Interface, which is also on order. This system will provide in-house data treatment capability requiring no central computer time. 
All other equipment for data collection has been received and includes the miniature LVDT's, with a common excitation power source and separately adjustable amplifier/demodulator modules with phase adjustment for finite accuracy, and an autoranging system grade digital voltmeter with BCD output and guarded input for rejection of R.F. noise.

Drawings for the wear-generating unit and information on equipment comprising the data collection and control units are available to facilities interested in duplication of the system.

A sufficient number of specimens of the materials tested originally will be tested on the new instrument to verify results from the prototype. Following this, work must begin on testing a substantial backlog of specimens developed at NBS and by various commercial manufacturers. Another source of wear specimens will likely be from the semi-precious and non-precious dental casting alloy project already underway at NBS. 
C. Base Metal Alloy Research

A study has been initiated with the objectives of determining the characteristics of base metal casting alloys and accessory materials related to the serviceability of these alloys for use in cast crowns and bridges; of determining the effects of fabrication techniques on the properties of the castings; and of utilizing this information for the development of improved techniques and to provide guidance for the development of improved alloys.

Increases in the price of gold during the last few years have led to demands for the use of base metal rather than gold alloys in dental restorations. Although the cost of the alloy is only a small percentage of the total cost of a restoration, a sizable overall saving in alloy cost could be made if base metal alloys could be substituted for gold alloys in the majority of cast restorations. Whether or not this would reduce the cost of dental care depends upon whether or not the use of base metal alloys increases other costs within the system. Additional costs might result from requirements for more expensive accessory materials and equipment, requirement of more time for fabrication, need for more remakes as a result of dimensional inaccuracy or other faults, or a shorter service life.

During the long period of time that gold casting alloys and the associated accessory materials have been used, the science and the art of casting these alloys have developed to the point that, with care, castings that are dimensionally accurate and satisfactory in other respects can be made routinely. The base metal alloy casting system has not been developed to this point. The base metal alloys have some disadvantages such as higher melting ranges relative to gold alloys, but it may well be that equally 
satisfactory restorations can be made from the base metal alloys if they are used with techniques and accessory materials that are adjusted to obtain optimum properties. To define in detail the suitability of base metal alloys for use in casting crowns and bridges, there is need for a comprehensive investigation of all materials and procedures involved. This would include characterization of present alloys in regard to the effects of composition on castability, surface finish and dimensional accuracy, as well as physical properties, characterization of investments in regard to effects of composition on setting characteristics, dimensional changes on setting and on heating, on strength at room and at high temperature and on alloy-investment interface reactions. In addition, the effects of fabrication techniques on properties of the castings should be determined, and correlation of clinical service with physical properties should be investigated. While the present study will touch upon all of these areas, emphasis will be placed on determining the capabilities of present alloys and accessory materials, with particular attention to dimensional accuracy.

Two laboratory modules have been assigned to this study. One has been fitted with new investing, casting and finishing equipment necessary for production of precision castings. The second module is being fitted with equipment for use in the production and investigation of porcelainfused-to-metal systems.

A prototype die design and a pattern production technique essential to the definition of casting accuracy have been tested and appear highly suitable. Five hardened stainless steel dies based on the prototype have been constructed and are now in use. Preliminary results indicate that, within the range of mold conditions, melting temperatures and commercially available non-precious metals and investments chosen, castings 
are generally undersize. Measurable differences in accuracy for small samples prepared under presumably identical, carefully controlled conditions suggested that there are either variations in the materials employed, or undetected variations in techniques. In order to insure that the techniques used in this study represent the best of the state of the art in pattern production, investing and casting procedures, visits are being made to a number of manufacturer research laboratories and commercial prosthetic laboratories. Comparisons with castings made in these laboratories indicate that so far as accuracy and reproducibility are concerned, techniques being use in this study are equal or superior to those used elsewhere.

It was noted that the phosphate investments necessary for the high melting porcelain bonding metals are associated with metal casting surfaces which are systematically rougher than the surfaces of metals cast into the gypsum bonded investments routinely used for lower melting crown and bridge gold alloys. In the critical test for dimensional accuracy applied in this study, it is nearly certain that the casting surface roughness associated with the phosphate investments exerts a significant influence on the measured goodness of fit of the casting. In order to quantify the degree of roughness, a profilometer suitable for the coarse roughness observed is being purchased. Measurements with the profilometer will be supplemented with optical and scanning electron microscope measurements.

An investigation of the dimensional changes on setting has been made on eight investments so that the relationships between these characteristics and the accuracy of castings can be determined. One hour after mixing, these investments show a range from near zero to approximately $1.5 \%$ in 
setting expansion when mixed at the manufacturer's liquid-powder ratio and liquid concentration for those investments for which a special liquid is supplied. Variations in setting expansion over approximately this same range can be obtained by varying the concentration of the liquid. In general, variations in liquid-powder ratio over a workable range had a smaller effect on setting expansion than did variations in 1iquid concentration. In contrast, setting time was affected more by liquid-powder ratio than by liquid concentration. Maximum temperatures observed in setting varied from approximately 40 to $85^{\circ} \mathrm{C}$ when the different investments were mixed as recommended by the manufacturer.

Apparatus for measurement of thermal expansion of the investments (and of alloys and porcelains) is on order. As the study progresses, it will be possible to make comparisons between dimensional changes of the investments and accuracy of the castings. This will provide additional information on the effects of other factors, such as surface roughness or the restraint of setting expansion by the pattern, on the accuracy of castings. 


\section{REFERENCES}

1. Loebenstein, W. V.: The Surface Area of Aggregates Applied to Dental Materials, J. Biomed. Materials Res. 9:35 (1975).

2. NBSIR 75-766: Properties and Interactions of Oral Structures and Restorative Materials, Annual Report prepared for National Institute of Dental Research.

2a. Loebenstein, W. V. and Kumpula, J. W.: New Method Evaluates Coupling Agents Bonding Polymer to Tooth Mineral, J. Dent. Res. (to be published).

3. Buonocore, M.: Adhesive Sealing of Pits and Fissures for Caries Prevention with the Use of U1traviolet Light, J. Amer. Dent. Assoc. $80: 324$ (1970).

4. Bowen, R. L.: Dental Filling Materials Comprising Viny 1 Silane Treated Fused Silica and a Binder Consisting of the Reaction Product of Bisphenol and Glycidyl Acrylate, U.S. Patent No. 3,066,112 (Nov. 1962).

5. Bowen, R. L.: Properties of a Silica-Reinforced Polymer for Dental Restorations, J. Amer. Dent. Assoc. 66:57 (1963).

6. Bowen, R. L.: Crystalline Dimethacrylate Monomers, J. Dent. Res. $49: 810$ (1970).

7. Barton, J. A.; Burns, C. L.; Chandler, H. H. and Bowen, R. L.: An Experimental Radiopaque Composite Material, J. Dent. Res. 52:731 (1973).

8. Chandler, H. H.; Paffenbarger, G. C.; MuIlineaux, A. L. and Bowen, R. L.: C1inical Evaluation of a Radiopaque Composite Material after Three and a Half Years, J. Dent. Res. 52:1128 (1973).

9. Chandler, H. H.; Paffenbarger, G. C.; Mullineaux, A. L. and Bowen, R. L.: Clinical Evaluation of a Tooth-Restoration Coupling Agent, J. Amer. Dental Assoc. 88:114 (1974).

10. Argentar, H. and Bowen, R. L.: Colored Charge-Transfer Complexes from N,N-Dimethyl-p-Toluidine, J. Dent. Res. 54:588 (1975).

11. Bowen, R. L. and Antonucci, J. M. : Dimethacrylate Monomers of Aromatic Diethers, J. Dent. Res. 54:599 (1975).

12. Antonucci, J. M. and Bowen, R. L.: Dimethacrylates Derived from Hydroxybenzoic Acids, J. Dent. Res. 55:8 (1976).

13. Bowen, R. L.: Adhesive Bonding of Various Materials to Hard Tooth Tissues. II. Bonding to dentin promoted by a surface-active comonomer, J. Dent. Res. 44:895 (1965). 
14. Buonocore, M. G.: A Simple Method of Increasing the Adhesion of Acrylic Filling Materials to Enamel Surfaces, J. Dent. Res. 34:849 (1955).

15. Eden, G. T.; Craig, R. G. and Peyton, F. A.: Evaluation of a Tensile Test for Direct Filling Resin, J. Dent. Res. 49:428 (1970).

16. Brauer, G. M. and Termini, D. J.: Bonding of Bovine Enamel to Restorative Resin: Effect of Pretreatment of Enamel, J. Dent. Res. $50: 151$ (1972).

17. Brauer, G. M.: Adhesion and Adhesives in Scientific Aspects of Dental Materials (von Fraunhofer, J. A., Ed) London, England, Butterworths, 1975, pp. 49-96.

18. Brauer, G. M. and Termini, D. J.: Grafting of Acrylates and Vinyl Chains onto Collagen with Ceric Initiator, J. Appl. Polym. Sci. $17: 2556$ (1973).

19. Brauer, G. M. and Termini, D. J.: Grafting of Polymeric Side Chains to Soft Tissues, J. Biomed. Mat. Res. 8:451 (1974).

20. Brauer, G. M. and Termini, D. J.: Modification of Collagenous Surfaces by Grafting Polymeric Side Chains to Collagen, in Applied Chemistry at Protein Interfaces, Baier, R. E., Ed., Advances in Chemistry, Vol. 145, Am. Chem. Soc., Washington, D.C., 1975, pp. 175-195.

21. Brauer, G. M.: Modification of Soft and Hard Tissues, in Dental Adhesive Materials, Moskowitz, Ward and Woolridge, Eds., Proceedings from Symposium held November 1973, New York, pp. 180-204.

22. Brauer, G. M. and Termini, D. J.: Chemical Modification of Bone Surfaces, 4th Bratislava IUPAC Sponsored International Conference on Modified Polymers and Their Preparation and Properties, Preprints of Short Communications, Bratislava 1975, Vol. I, p. 10.

23. Brauer, G. M. and Termini, D. J.: Polymers and Their Preparation and Properties, Preprints of short communications, Bratislava, 1975, Vol. I, p. 10 .

24. Brauer, G. M.; Termini, D. J. and Levy, S.: Chemical Modifications of Hard Tissues - I. Bone, Accepted for Publication in 1977 by J. Dent. Res.

25. Frish, K. C.; Klempner, D.; Mukhergee, S. K. and Frisch, H. L.: Stress-Strain Properties and Thermal Resistance of PolyurethanePolyepoxide Interpenetrating Polymer Networks, J. Appl. Polymer Sci. $18: 689$ (1974).

26. Himics, R. J.: Novel Photosensitive Polymers, Am. Chem. Soc. Div. of Organic Coatings and Plastics Chemistry. Papers presented at the Dallas meeting, 33:274 (1973). 
27. Kulkarni, R. K.; Bartok, D. E. and Leonard, F.: Initiation of Polymerization of Alkyl-2-Cyanoacrylates in Aqueous Solutions of Glycine and its Derivatives, J. Polym. Sci. Al, 9:2977 (1971).

28. Lee, H.; Swartz, M. L. and Culp, G.: Static Loading Test of Dental Adhesion, J. Dent. Res. 48:211 (1969).

29. Khowassah, M. A. and Shippy, R. L. : In Vitro Investigation of Adhesive Strength of Cyanoacrylate Bonds to Human Hard Tooth Structures, J. Biomed. Mater. Res. 5:159 (1971).

30. Beech, D. R.: Bonding of Alkyl 2-Cyanoacrylates to Human Dentin and Enamel, J. Dent. Res. 51:1438.

31. Beech, D. R. and Kurer, H. G.: An In Vivo Study of Cyanoacrylate as an Adhesive for Composite Restorations. Program and Abstracts of Papers, 53rd General Session, International Association for Dental Research, London, April 1975, L-356. 
NBS.1 | AA (REV. 7-73)

\begin{tabular}{|c|c|c|c|}
\hline $\begin{array}{l}\text { U.S. DEPT. OF COMM. } \\
\text { BIBLIOGRAPHIC DATA } \\
\text { SHEET }\end{array}$ & $\begin{array}{l}\text { 1. PUIBICATION OR REPORT NO. } \\
\text { NBSIR 76-1095 }\end{array}$ & $\begin{array}{l}\text { 2. Gov't Accession } \\
\text { No. }\end{array}$ & 3. Recipient's Accession No. \\
\hline \multirow{2}{*}{\multicolumn{3}{|c|}{$\begin{array}{l}\text { 4. TITLE AND SUBTITLE } \\
\qquad \begin{array}{l}\text { Properties and Interactions of Oral Structures } \\
\text { and Restorative Materials. }\end{array}\end{array}$}} & \multirow{2}{*}{ 5. Publication Date } \\
\hline & & & \\
\hline \multicolumn{3}{|c|}{ 7. AUTHOR(S) James M. Casse1 } & 8. Performing Organ. Report Nw. \\
\hline \multirow{2}{*}{\multicolumn{3}{|c|}{$\begin{array}{l}\text { 9. PERFORMING ORGANIZATION NAME AND ADDRESS } \\
\qquad \begin{array}{l}\text { NATIONAL BUREAU OF STANDARDS } \\
\text { DEPARTMENT OF COMMERCE } \\
\text { WASHINGTON, D.C. } 20234\end{array}\end{array}$}} & $\begin{array}{l}\text { 10. Project/Task/Work Unit No. } \\
3110561\end{array}$ \\
\hline & & & $\begin{array}{l}\text { 11. Contract/Grant No. } \\
\text { NIDR YO1-DE-40015 }\end{array}$ \\
\hline \multicolumn{3}{|c|}{$\begin{array}{l}\text { 12. Sponsoring Otganization Name and Complete Address (Street, City, State, ZIP) } \\
\text { Restorative Materials Program } \\
\text { National Institute of Dental Research, NIH } \\
\text { Westwood Building } \\
\text { Bethesda, Maryland } 20014\end{array}$} & $\begin{array}{l}\text { 13. Type of Report \& P'riod } \\
\text { Covered Report } \\
\text { Annual Report } \\
\text { U1y } 1,1975 \text {-June } 30,1976 \\
\text { 14. Sponsoring Agency Code } \\
\text { NIDR }\end{array}$ \\
\hline
\end{tabular}

15. SUPPLEMENTARY NOTES

16. ABSTRACT (A 200-word or less factual summary of most significant information. If document includes a significant bibliography or literature survey, mention it here.)

A diversity of techniques is being directed toward development of new and improved dental restorative and caries-preventive materials. These have included: surface characterization of dental materials and coupling agent-coated hydroxyapatite by water adsorption; further evaluation of a novel testing approach for investigating the adhesive capability of coupling agents; synthesis of selected monomers for potential application as components of a dental composite restorative system or a pit and fissure sealant application; and investigation of techniques such as grafting with 2-cyanoacrylates and urethanes containing free isocyanate groups for modifying natural tooth and bone surfaces so as to achieve a more compatible surface for adhesion. Failure of the data acquisition and control system of a prototype pin on disc in vitro wear test procedure for dental restorative materials to record data consistently and to maintain proper measurement point trigger position have dictated construction of a new wear test unit that incorporates the successful design of the prototype unit, but that will allow for testing of multiple specimens and should permit data to be accumulated with a confidence level of $95 \%$, as compared to the $90 \%$ level previously attained. Procedures have been developed for the investigation of non-precious alloys used in crown and bridge application.

17. KEY WORDS (six to twelve entries; alphabetical order; capitalize only the first letter of the first key word unless a proper name; separated by semicolons)

Adhesion; adsorption; alloys; composites; dental; grafting; investments; polymer; resin; wear.

18. AVAILABILITY $\bar{X}$ Unlimited

For Official Distribution. Do Not Release to NTIS

Order From Sup. of Doc., U.S. Government Printing Office Washington, D.C. 20402, SD Cat. No. CI3

Order From National Technical Information Service (NTIS) Springfield, Virginia 22151

\begin{tabular}{|c|c|}
\hline $\begin{array}{l}\text { 19. SECURITY CLASS } \\
\text { (THIS REPURT) } \\
\text { UNCL ASSIFIED }\end{array}$ & 21. NO. OF PAGES \\
\hline $\begin{array}{l}\text { 20. SECURITY CLASS } \\
\text { (THIS PAGE) }\end{array}$ & 22. Price \\
\hline UNCLASSIFIED & \\
\hline
\end{tabular}



